\title{
Appendix 1. Catalogue of Human Remains from Schleinbach
}

Social Relations, Deprivation and Violence at Schleinbach, Lower Austria. Insights from an Interdisciplinary Analysis of the Early Bronze Age Human Remains

\author{
Doris Pany-Kucera \\ Michaela Spannagl-Steiner \\ Lukas Waltenberger \\ Walther Parson \\ Christina Strobl \\ Barbara Rendl \\ Lukas Janker \\ Fabian Kanz \\ Katharina Rebay-Salisbury
}

The following catalogue contains a systematic description of over 60 Bronze Age individuals from settlement features and graves from Schleinbach in Lower Austria. The schemes indicate preserved skeletal elements in red, green stains in green.

Image credits: Skeletal representation scheme after M. Schultz, Zentrum Anatomie Göttingen 1994, adapted for the Natural History Museum Vienna by W. Reichmann.

doi: 10.1553/archaeologia104s13-A 


\section{Schleinbach, Feature 9A (Group 1), NHM AA Inv. no. 27619}

Sex: female, female expression of sexually dimorphic traits in the cranium and pelvis Age: 45-55 years, dental wear (> III, oblique dental wear in two maxillary molars, but no intravital tooth loss, mandibular teeth uniformly worn), coronal and sagittal sutures completely fused, lambda suture partially closed ( $>50$ years)

TCA age (counts): 25.5/25.6 \pm 5 years

Body height: $163 \mathrm{~cm}$

Bone surface preservation: moderately eroded

Green stains: mastoid process, cranial base of occipital bone, right zygomatic process, right mandible and teeth, 2 cervical vertebrae, both clavicles, right proximal humerus, right distal radius, carpals, metacarpals and phalanges of the right hand

Pelvic features: right preauricular sulcus is moderately developed (shape $\mathrm{r} / \mathrm{l}: \mathrm{f}-\mathrm{f}-\mathrm{f} / \mathrm{f}-\mathrm{f}-$, stage $\mathrm{r} / \mathrm{l}: 3 / 2)$; some exostoses are located in the anterior/superior part of the iliac auricular facet (stage $r / 1: 2 / 2$ )

Stress/bone reactions: none detected (bad preservation of long bone surfaces)

Trauma: possible parry fracture in the distal portion of the left ulna, no displacement, but callus formation

Degenerative changes: changes on the first phalanx of the right hand

Other: granular foveolae on the lamina interna of the frontal and parietal bones

Anatomical variation:-

Comments: long bone measurements: left femur $=443 \mathrm{~mm},{ }^{14} \mathrm{C}$ and $\mathrm{C} / \mathrm{N}$ isotope samples taken from ribs, TCA samples from FDI 22 and FDI 41

Comments: male sex according to Weninger 1954, female sex according to TeschlerNicola 1992

\section{Schleinbach, Feature 9B (Group 1), NHM AA Inv. no. 27620}

\section{Sex: undetermined}

Age: 1.5 years, size of cranial fragments and dental development of maxillary incisor 1 Body height: -

Bone surface preservation: moderately eroded (cranial fragments and maxillary incisor 1) Green stains: none detected

Pelvic features, stress/bone reactions, trauma, degenerative changes, other, anatomical variation:-

Comments: skeletal remains found with a female individual from Feature 9A
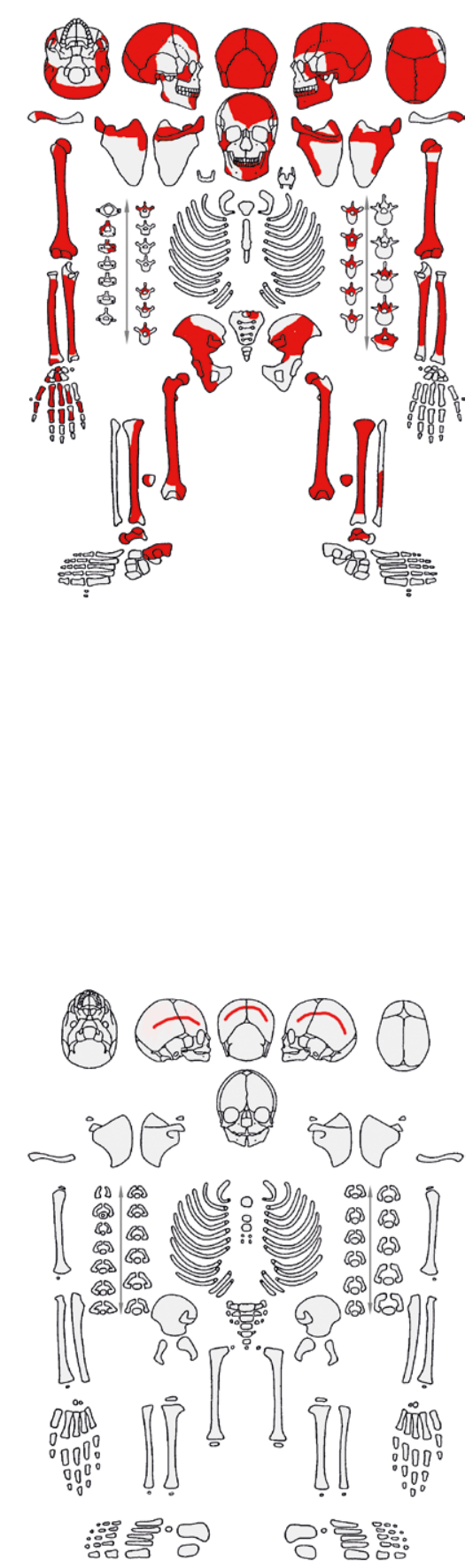
Schleinbach, Feature 10 (Group 1), NHM AA Inv. no. 27621

Sex: undetermined

Age: c. 10-12 years, status of dentition and epiphyseal fusion

Body height: c. $125 \mathrm{~cm}$

Bone surface preservation: slightly eroded

Green stains: the right parietal bone is partially stained, both temporal bones, right occipital bone, (C1-7) both clavicles, right scapula, right humerus, both radii and ulnae, numerous ribs, carpals, metacarpals and phalanges of the hands, left knee

Pelvic features: -

Stress/bone reactions: none detected

Trauma: none detected

Degenerative changes: none detected

Other: persisting right deciduous $2^{\text {nd }}$ molar (MM2) in the upper and lower jaw; substantial calculus build-up especially in the lower jaw

Anatomical variation: -

Comments: measurement of the diaphyseal length: left femur $=309 \mathrm{~mm}$, additional skeletal fragments of an adult individual and some animal bones

\section{Schleinbach, Feature 11 (Group 1), NHM AA Inv. no. 27622}

Sex: female, female expression of sexually dimorphic traits in the cranium and pelvis Age: 45-55 years, dental wear (> III), cranial suture fused

Body height: $156 \mathrm{~cm}$

Bone surface preservation: slightly eroded

Green stains: temporal bones, mastoid process, occipital bone, left zygomatic bone, left mandible, $1^{\text {st }}$ and $2^{\text {nd }}$ cervical vertebra, a fragment of left scapula, left humerus, right radius distal

Pelvic features: left preauricular sulcus is wide and y-shaped (shape r/l: -/f-f-f, stage r/l: $0 / 4$ ); bilaterally developed clearly defined pubic tubercle (stage $r / 1: 3 / 2$ ) and a sharp-edged pecten ossis pubis; large and deep lesions present $(>2 \mathrm{~mm})$ in the middle and lower third of dorsal pubic surface (stage r/l: 3/3); slight ventral pubic lesions (stage r/l: 2/2); sharp-edged attachment of medial gluteal muscles; slightly developed sacral preauricular extension on the right side (stage $r / 1: 2 / 0)$

Stress/bone reactions: healed sinusitis maxillaris in the form of remodelled new bone apposition in the left maxillary sinus

Trauma: none detected

Degenerative changes: signs of osteoarthrosis/osteoarthritis in both knee joints, with large exostotic bone growth especially at the joint margins, in the femora for the most part medially located (only a fragmentary preservation of the right side), in the tibiae mainly in the anterior and medial part of the proximal joint, cystic lesion on the lateral side of the right tibia Other: granular foveolae on the internal layer alongside the sagittal suture; a circular focal lytic lesion on the occipital bone (protuberance region, c. $13 \times 13 \times 10 \mathrm{~mm}$, contra WENINGER 1954b, 55, who interpreted this lesion as a trepanation)

Several carious lesions at the dental cervices; strongly developed calculus especially in the lower jaw; asymmetrical abrasion of the teeth in the upper jaw

Anatomical variation: -

Comments: long bone measurements: left femur $=418 \mathrm{~mm}$
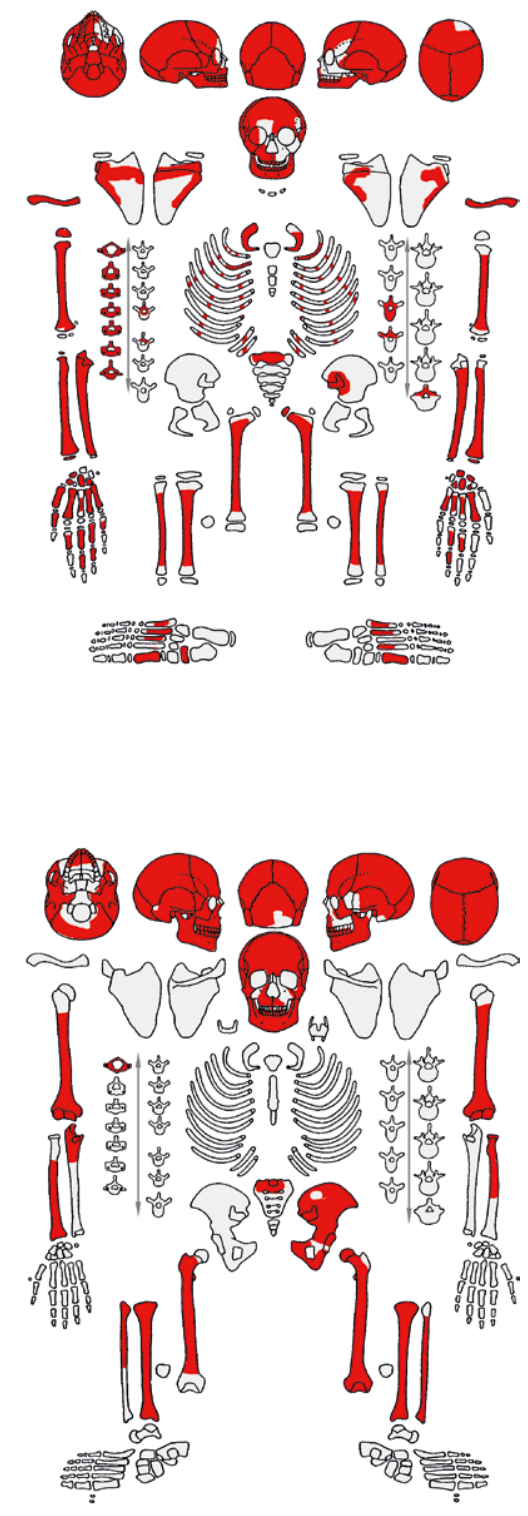
Schleinbach, Feature 12 (Group 1), NHM AA Inv. no. 27623

Sex: undetermined

Age: 5-6 years, dental development

Body height: -

Bone surface preservation: slightly eroded

Green stains: left side of the viscerocranium and right mandible, right clavicle, right scapula and proximal portion of right humerus, right $1^{\text {st }}$ rib, phalanges of the right hand

Pelvic features: small groove bilaterally visible in the preauricular region

Stress/bone reactions, trauma, degenerative changes: -

Anatomical variation: none detected

Other: intravital chipping of the right $1^{\text {st }}$ maxillary deciduous incisor

Comments: no measurements of diaphyseal length possible; cranium exhibits numerous post-mortem fracture lines

Comment 2: ${ }^{14} \mathrm{C}+\mathrm{C} / \mathrm{N}$ sample: rib
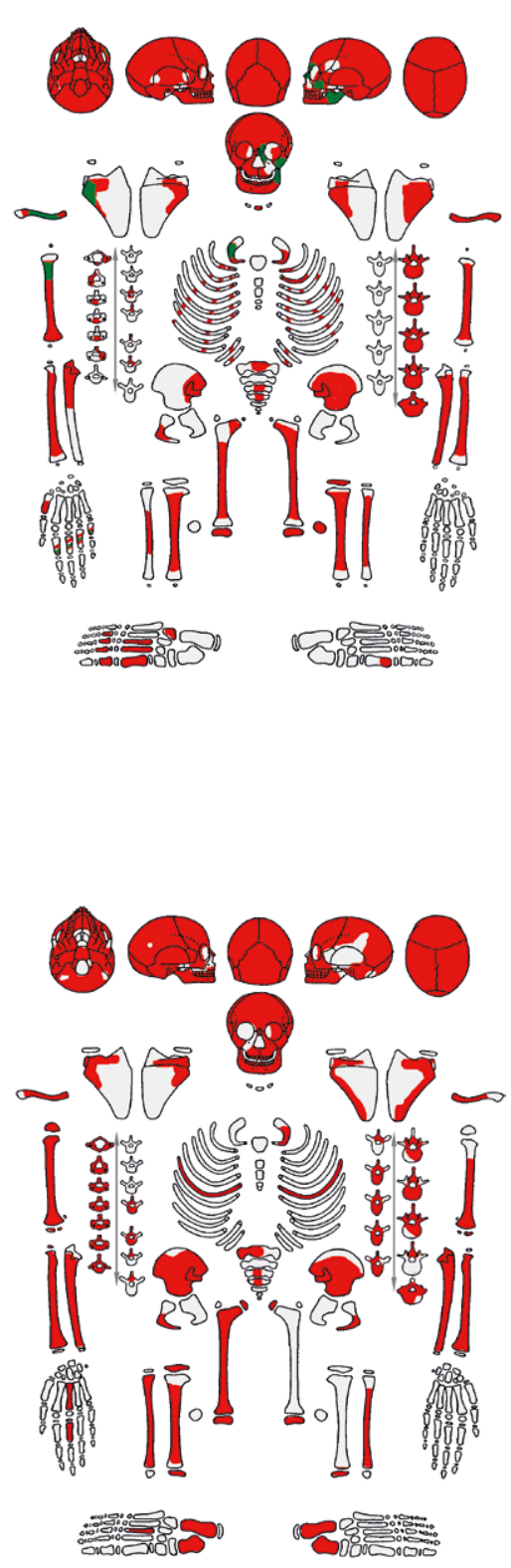

Schleinbach, Feature 13 (Group 1), NHM AA Inv. no. 27624

\section{Sex: undetermined}

Age: 13-15 years, dental development (M2 in masticatory plane, > 14 years), but diaphysis length points to a 10-12-year-old individual

Body height: $120-124 \mathrm{~cm}$

Bone surface preservation: moderately eroded

Green stains: right side of the temporal bone, cranial base, zygomatic process, mandible and teeth, clavicle, scapula and proximal humerus; $1^{\text {st }}$ ribs; all cervical vertebrae and two thoracic vertebrae

Pelvic features:-

Stress/bone reactions: bilateral cribra orbitalia visible as foramina in the orbital roofs; local periosteal reaction/new bone apposition $($ c. $10 \times 20 \mathrm{~mm}$ ) in the dorsoproximal shaft of the right ulna; pleuritis visible as a porous new bone layer on the pleural side of three ribs

Trauma: none detected

Degenerative changes: none detected

Other: LEH (enamel hypoplasia): severity stage 2, 2 fine hypoplastic lines in maxillary first and 1 in second incisors; further, 2 hypoplastic lines in mandibular second incisor and 1 in the right canine, corresponding to a formation age of 2.5 and 3.5 years

Anatomical variation: upper $2^{\text {nd }}$ molar exhibits an accessory protuberance; foramina caeca on all lower molars

Comments: measurements of diaphyseal lengths: right humerus $=210 \mathrm{~mm}$, left femur $=$ $300 \mathrm{~mm}$; discrepancy in age estimation between dentition and bone growth 
Schleinbach, Feature 14 (Group 1), NHM AA Inv. no. 27625

Sex: female?, female expression of sexually dimorphic traits in the cranium and pelvis Age: 15-18 years, dentition status (M3 not erupted); epiphyseal fusion in the distal humerus, proximal radius, ulna, and y-shaped epiphysis in the acetabulum Body height: $151 \mathrm{~cm}$

Bone surface preservation: strongly eroded

Green stains: left side of zygomatic process, clavicle, scapula, radii and ulnae

Pelvic features: preauricular sulcus shape $r / \mathrm{l}: \mathrm{f}-\mathrm{i}-\mathrm{f} / \mathrm{i}-\mathrm{i}-\mathrm{f}$, stage $\mathrm{r} / \mathrm{l}: 2 / 1$; pectineal line is well defined

Stress/bone reactions: remodelled periosteal reactions (striations) in the shaft of the femora and tibiae; possible case of rickets - bending in the anterodistal part of both femora and both tibiae exhibit a lateral flexion in the upper part with strong muscle attachments

Trauma: none detected

Degenerative changes: none detected

Other: LEH (enamel hypoplasia): severity stage 3, 1 hypoplastic line in mandibular left second incisor; further, 2 hypoplastic lines in mandibular left canine, corresponding to a formation age of 2.5 and 3.4 years

Anatomical variation: none detected

Comments: long bone measurements: right tibia $=340 \mathrm{~mm}$, right femur $=399 \mathrm{~mm}$; the surface of some bones are covered with sintering, male sex according to WENINGER 1954, female sex according to TESCHLER-NICOLA 1992

\section{Schleinbach, Feature 15 (Group 1), NHM AA Inv. no. 27626}

Sex: male, male expression of sexually dimorphic traits in the cranium, mandible, and pelvis Age: 21-25 years, no cranial suture closure, dental wear (Ic)

Body height: c. $161 \mathrm{~cm}$

Bone surface preservation: moderately eroded

Green stains: none detected

Pelvic features: preauricular sulcus shape $\mathrm{r} / \mathrm{l}: \mathrm{mm-/--}$, stage $\mathrm{r} / \mathrm{l}: 1 / 0$

Stress/bone reactions: cribra orbitalia represented as a cluster of fine foramina in the left orbital roof

Trauma, degenerative changes, other, anatomical variation: none detected

Comments: long bone measurements: right femur $=435 \mathrm{~mm}$, buried close to individual in Feature 18 (double burial?)
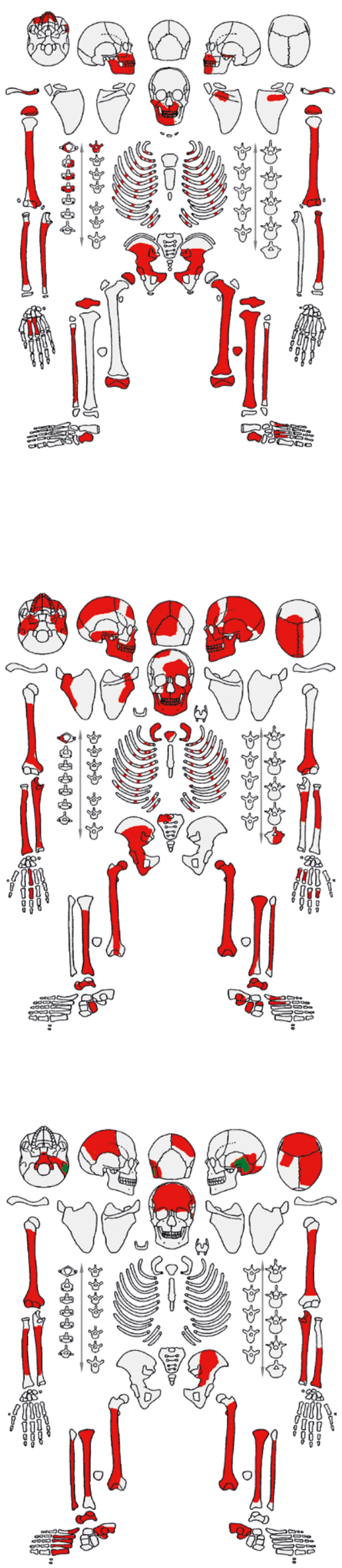

Schleinbach, Feature 16 (Group 1), NHM AA Inv. no. 27627

Sex: female?, female expression of some of the sexually dimorphic traits in the cranium. Indifferent expression of pelvic features. Robustness of the long bones

Age: 21-25 years, no cranial suture fusion, epiphyseal fusion finished; M3 not fully developed

Body height: $164-165 \mathrm{~cm}$

Bone surface preservation: strongly eroded

Green stains: left temporal bone

Pelvic features, stress/bone reactions, trauma and degenerative changes: none detected, severely eroded

Other: only isolated teeth, one upper I1, two lower PM1 and two M3 (root not completely developed)

Anatomical variation: none detected

Comments: long bone measurements: left ulna $=263 \mathrm{~mm}$, left tibia $=394 \mathrm{~mm}$; cranial internal layer and some postcranial skeletal elements are covered with sinter - no evaluation possible; 25-30-year-old male according to WENINGER 1954, juvenile adult female according to Teschler-Nicola 1992 


\section{Schleinbach, Feature 17 (Group 1), NHM AA Inv. no. 27628}

Sex: female?, female expression of sexually dimorphic traits in the cranium and pelvis; gracile stature

Age: 14-15 years, dentition and mineralization (M2 in masticatory plane, M3 still in the jawbone); epiphyseal fusion not finished (distal humerus, distal metacarpals, sacrum S1)

Body height: -

Bone surface preservation: moderately eroded

Green stains: internal layer of parietal bones, and on the right side of the temporal bone, maxillary molars, mandible, cervical vertebrae, humerus, carpals and metacarpals of the right hand

Pelvic features:-

Stress/bone reactions: pleuritis visible as a fine porous new bone layer on the dorsal part of the inner surface of two ribs

Trauma: none

Degenerative changes: none detected

Other: LEH (enamel hypoplasia): severity stage 3, 1 hypoplastic line in mandibular right second incisor and further, with severity stage 2, 2 hypoplastic lines in mandibular canines, corresponding to a formation age of 2.9 and 3.5 years; bilateral localized new bone apposition, possible haematoma, in the dorsal mid-shaft of the tibiae

Anatomical variation: none detected

Comments: no long bone measurements possible; additional skeletal remains of an adult individual and some animal bones

\section{Schleinbach, Feature 18 (Group 1), NHM AA Inv. no. 27629}

Sex: female?, female expression of sexually dimorphic traits in the cranium but skeletal robusticity $(+1)$

Age: 30-35 years, cranial suture fusion (S3 fused), dental wear (IIc)

Body height: -

Bone surface preservation: moderately eroded

Green stains: left temporal bone, one cervical vertebra, some rib fragments

Pelvic features:-

Stress/bone reactions: perisinusitis manifested as remodelled new bone apposition in the confluens sinuum of the occipital bone

Trauma: none detected

Degenerative changes: none detected

Other: internal layer of the left parietal bone reveals deep vessel impressions

Anatomical variation: none detected

Comments: no long bone measurements possible; 40-45-year-old female according to

Weninger 1954, male adult according to TESCHLER-Nicola 1992

\section{Schleinbach, Feature 22 (pit), NHM AA Inv. no. 27630}

\section{Sex: undetermined}

Age: $3.5-4.5$ years, status of dentition and mineralization (c. 4 years)

Body height: -

Bone surface preservation: strongly eroded

Green stains: proximal portion of right ulna and radius, and distal portion of left ulna and radius

Pelvic features, stress/bone reactions, trauma, degenerative changes, other, anatomical variation:-

Comment: no measurements possible; ${ }^{14} \mathrm{C}$ and $\mathrm{C} / \mathrm{N}$ isotope samples taken from ribs
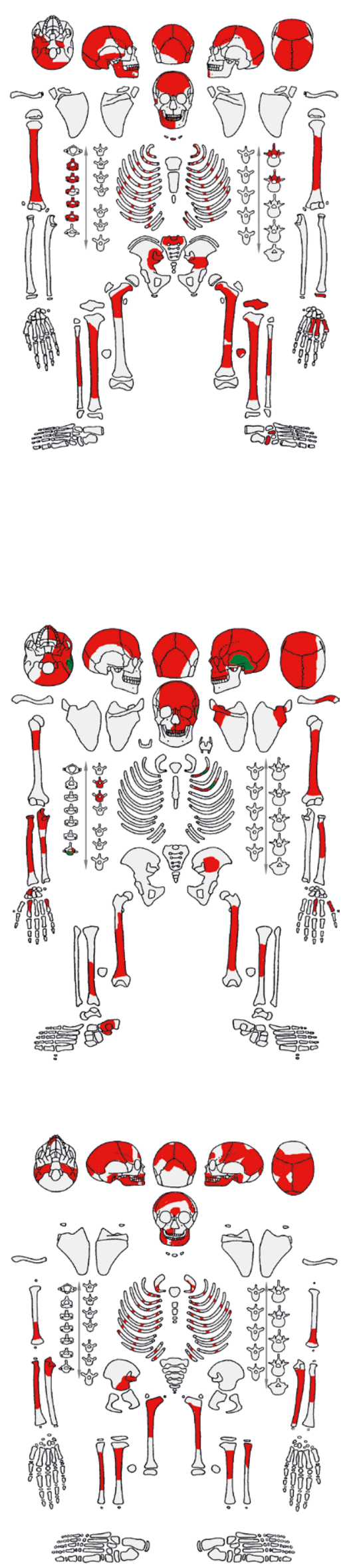
Schleinbach, Feature 23 (?) (Group 1), NHM AA Inv. no. 27631

Sex: undetermined

Age: 6-7 years, dentition and mineralization (6-7 years), diaphyseal length

Body height: c. $105 \mathrm{~cm}$

Bone surface preservation: moderately eroded

Green stains: none detected

Pelvic features: -

Stress/bone reactions, trauma, degenerative changes, other, anatomical variation: none detected

Comments: diaphyseal measurement of the right femur $=225 /-\mathrm{mm}$; fracture lines on some cranial fragments and long bone elements

Schleinbach, Feature 27 (Group 1), NHM AA Inv. no. 27632

Sex: undetermined

Age: $0.75-1.25$ years, diaphyseal length

Body height: $70-74 \mathrm{~cm}$

Bone surface preservation: strongly eroded

Green stains: left petrosal bone

Pelvic features, stress/bone reactions, trauma, degenerative changes, other, anatomical variation: -

Comments: diaphyseal measurement of femur $=120 /-\mathrm{mm}$; nearly all cranial fragments show post-mortal fracture lines
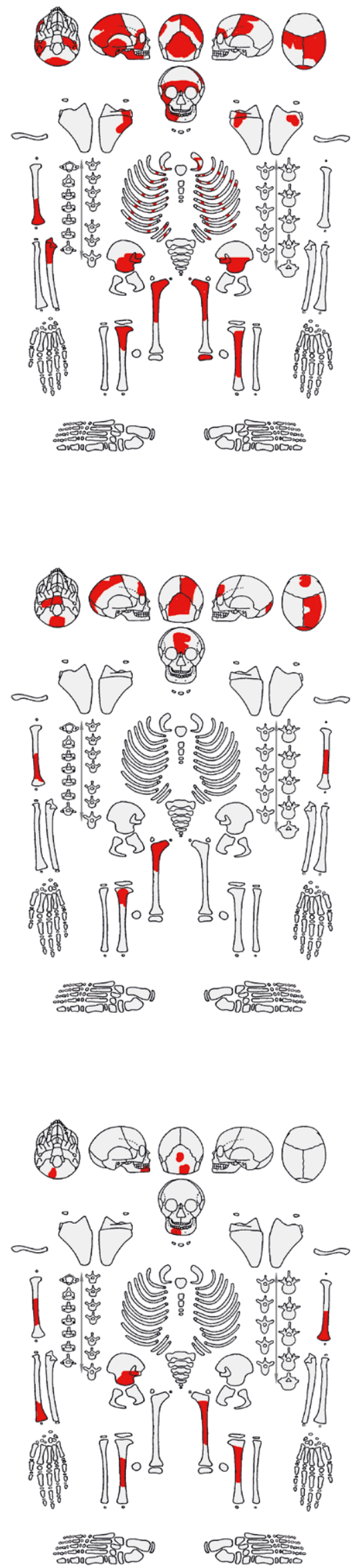

Schleinbach, Feature 28 (Group 1), NHM AA Inv. no. 27633

Sex: undetermined

Age: 1.5-2.5 years, primary dentition and mineralization

Body height: -

Bone surface preservation: strongly eroded

Green stains: none detected

Pelvic features, stress/bone reactions, trauma, degenerative changes, other, anatomical variation: -

Comments: no diaphyseal measurements possible; navicular bone of an additional adult individual, fragments of animal bones and shells 
Schleinbach, Feature 29 (Group 1), NHM AA Inv. no. 27634

Sex: female, female expression of sexually dimorphic traits in the cranium and pelvis, but not in the mandible

Age: 30-35 years, cranial fusion (S3/4, C3 fused), dental wear (IIb-IIIa), clavicle (> stage 3), facies symphysialis (stage VI)

Body height: c. $161 \mathrm{~cm}$

Bone surface preservation: moderate, nearly complete skeleton (surface partly covered with sintering)

Green stains: none detected

Pelvic features: right preauricular sulcus consists of one deep groove, the left one consists of two deep grooves with a closed border (shape $\mathrm{r} / \mathrm{l}$ : f-f-f/ f-f-f, stage r/l: 4/4); bilaterally developed sacral preauricular extensions (right side: $\mathrm{h}=12 \mathrm{~mm}, \mathrm{w}=4 \mathrm{~mm}$; left side: $\mathrm{h}=12 \mathrm{~mm}$, $\mathrm{w}=5 \mathrm{~mm}$ ), no related changes in the iliac bones; bilateral modification at upper dorsal end of sacral auricular facet, an elevated and delimited elongation, corresponding with ilium on the left side, right iliac side eroded; bilaterally developed irregular exostotic structures in the area of the pubic tubercle - but no distinct extended pubic tubercle; possible dorsal pubic pitting in the right pubic bone (stage $\mathrm{r} / \mathrm{l}$ : $2 / 1$ - partially sintered); ventral pubic surface shows rim-like exostotic structures running parallel to the symphysis and irregular lesions, especially in the upper third (stage $\mathrm{r} / \mathrm{l}: 2 / 2$ )

Stress/bone reactions: none detected

Trauma: none detected

Degenerative changes: caput mandibulae appears flattened bilaterally; big irregular fovea on right femoral head

Other: -

Anatomical variation: bilaterally occurring foramen olecranon

Comments: long bone measurements: right femur $=435 \mathrm{~mm}$, body height $=\mathrm{c} .161 \mathrm{~cm}$ (RuFF et al. 2012)

\section{Schleinbach, Feature 30 (Group 1, double burial), NHM AA Inv. no. 27635}

Sex: male, male expression of sexually dimorphic traits in the cranium and pelvis, but long bone gracility

Age: 27-30 years, dental wear (IIb), clavicle (> stage III), symphyseal facet (stage V)

TCA age: $37 / 38.4 \pm 5$ years

Body height: $163 \mathrm{~cm}$

Bone surface preservation: moderately eroded

Green stains: none detected

Pelvic features: preauricular sulcus (shape r/l: m-m-m/m-m-m, stage $\mathrm{r} / \mathrm{l}$ : 1/1); slight lesions on ventral pubic surface (stage r/l: $2 / 2$ )

Stress/bone reactions: none detected

Trauma: cranial polytrauma, peri-mortem fractures: 1 . blunt force trauma, of burst fracture type, round to oval shape (size not measurable, fragmented) with sharp margins, chipping at internal lamina, and radial fracture lines in the left parietal bone, continuing through suprameatal spine and external acoustic meatus (similar to the cranium of grave 31 ); 2 . viscero-cranial fracture of the left anterior part of the mandible extending from the mentum to the premolars, including chipping of the crowns down to the root of the left maxillary and mandibular canine and premolars; fracture of the left superior and inferior pubic ramus of unclear status (lateral compression type 1, anterior pelvic ring fracture)

Degenerative changes: none detected

Other: lumbosacral transitional vertebra L5/S1 (false-joint formation at the left transverse process of the fifth lumbar vertebra with the left lateral part of the sacrum)

Anatomical variation: facies poirier to the right femoral head

Comments: long bone measurements: left femur $=440 \mathrm{~mm}$; aDNA sample taken from FDI $34,{ }^{14} \mathrm{C}$ and $\mathrm{C} / \mathrm{N}$ isotope sample taken from femur, TCA sample taken from FDI 21; buried in double grave with the individual from Feature 31
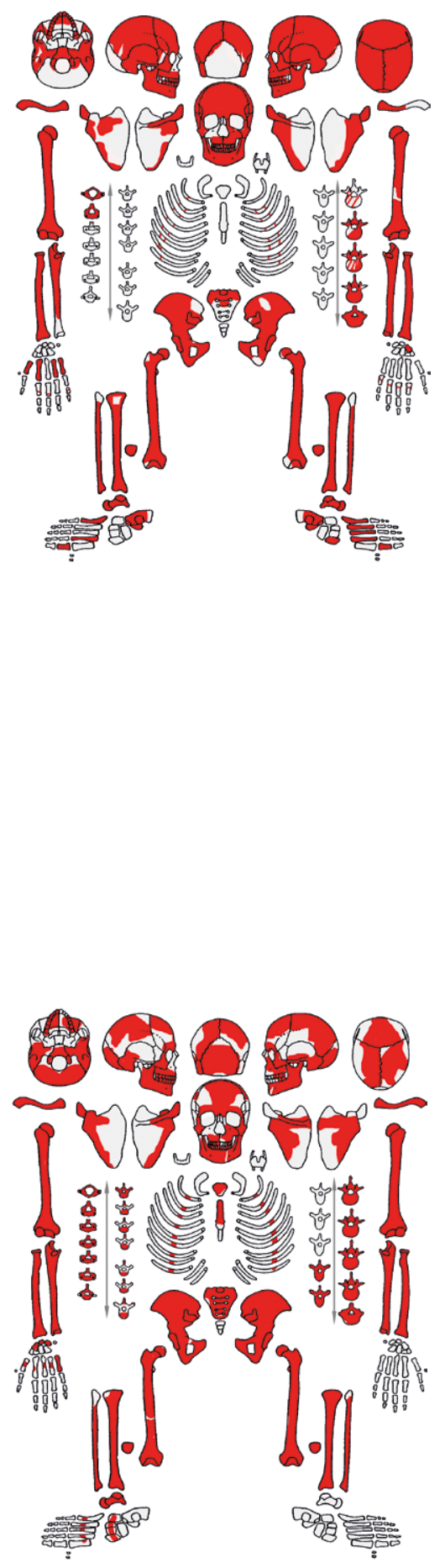


\section{Schleinbach, Feature 31 (Group 1, double burial), NHM AA Inv. no. 27636}

Sex: male, male expression of sexually dimorphic traits in the cranium and pelvis

Age: 30-35 years, dental wear (IIb), clavicle (> stage III), cranial suture fusion (S3)

TCA age: $32.8 / 34 \pm 5$ years

Body height: $172 \mathrm{~cm}$

Bone surface preservation: moderately eroded

Green stains: none detected

Pelvic features: small, well-defined groove below the inferior margin of the right auricular facet $(10 \times 4 \mathrm{~mm})$ preauricular sulcus (shape $\mathrm{r} / \mathrm{l}: \mathrm{m}-\mathrm{m}-\mathrm{m} / \mathrm{m}-\mathrm{m}-\mathrm{m}$, stage $\mathrm{r} / \mathrm{l}: 1 / 1$ )

Stress/bone reactions: none detected

Trauma: peri-mortem cranial fractures, 1 . burst fracture of half-rounded shape $(60 \times 60 \mathrm{~mm})$ with characteristic fracture lines in the left parietal bone (near coronal suture) and chipping of the internal layer of the cranium; 2. sharp-edged fracture lines on temporal bone and zygomatic process; 3 . intravital compression fracture on the left side of the fifth lumbar vertebra; 4. intravital traumatic inferior subluxation of the shoulder joint, including the development of a new, smooth joint surface (size $20 \times 15 \mathrm{~mm}$ ) at the lower border of the left glenoid cavity of the scapula, but no alteration is visible in the humeral head

Degenerative changes: degenerative new bone formation at the joint margin of both knees; distinct exostoses on the tuberositas tibiae; both femora show strong expression of the adductor muscle attachment (similar to the adult male of grave 60)

Other: strong calculus formation on the teeth

Anatomical variation: bilaterally developed facies poirier to the femoral head/neck

Comments: long bone measurements: right femur $=474 \mathrm{~mm}$; DNA sample taken from FDI 45, TCA sample taken from FDI 25; buried in double grave with individual from Feature 30

\section{Schleinbach, Feature 32/1 (pit), NHM AA Inv. no. 27637}

Sex: female?, mainly female expression of the sexually dimorphic traits of the skull Age: 25-29 years, dental wear (Ic, isolated teeth), no cranial suture closure ( $<30$ years) Body height: -

Bone surface preservation: strongly eroded (surface of lamina interna partially covered with sinter)

Green stains: none detected

Pelvic features: -

Stress/bone reactions: none detected

Trauma, degenerative changes, other, anatomical variation:-

Comment: no measurement of long bones possible

\section{Schleinbach, Feature 32/2 (pit), NHM AA Inv. no. 27638}

Sex: female?, female expression of sexually dimorphic traits in cranium, iliac bone, and long bones

Age: 35-45 years, cranial suture fusion (coronal part still open, sagittal 2/3 and lambdoid sutures partially fused)

Body height: -

Bone surface preservation: moderately eroded

Green stains: none detected

Pelvic features: sharp margin with slight new bone formation on the superior part of the right auricular facet

Stress/bone reactions: porotic hyperostosis visible as slight pitting in the external layer of the skull

Trauma, degenerative changes, other, anatomical variation: none detected

Comments: no long bone measurements possible; occipital bone of an additional individual with remodelled new bone formations in the sinus sagittalis area
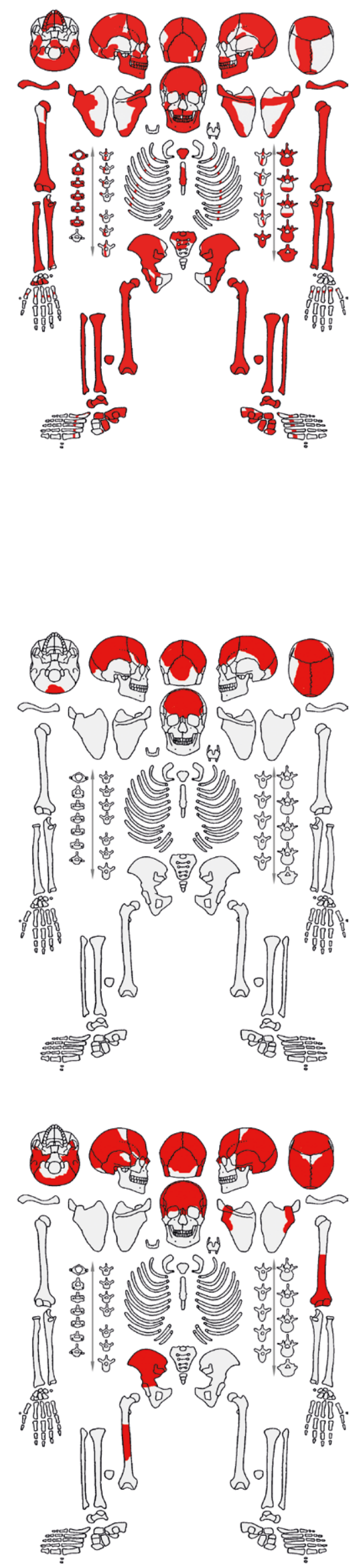
Schleinbach, Feature 55 (pit), NHM AA Inv. no. 27639

Sex: undetermined

Age: 14-18 years

Comment: The skeletal remains were not available for evaluation. Karl Kriegler's ad hoc assessment: probably female, young (RETTENBACHER 2004, 83). The incomplete epiphyseal closure of the distal ends of the femora visible in the photograph(reprinted in RETTENBACHER 2004, 154 and Pl. 50/2) suggest an age of 14-18 years

\section{Schleinbach, Feature 56 (pit), NHM AA Inv. no. 27640}

Sex: female?, indifferent expression of sexually dimorphic traits in the cranium and mandible but pelvic features are distinctly female

Age: 40-55 years, fusion of cranial suture (S3, S4 fused), dental wear (IIIc/IV, intravital tooth loss and periapical inflammation), pubic symphysis (stage $\mathrm{X}$ )

TCA age: $26.2 / 46.2 \pm 5$ years

Body height: (160-162 cm)

Bone surface preservation: weakly eroded

Green stains: none detected

Pelvic features: clearly defined true preauricular sulcus with a structured surface (shape $\mathrm{r} / \mathrm{l}$ : f-f-f/f-f-f, stage r/l: 4/4); moderately developed exostoses at auricular facets (stage r/l: 2/2); commencing ossific bridging ventro-superiorly at right sacroiliac joint (potentially influenced by multiple fracture of the sacrum); moderate lesions and exostoses (stage r/l: $2 / 0$ ) on the right ventral and dorsal pubic surfaces; slight margo auricularis groove (stage r/l: $2 / 1$ ) on the right side of the sacrum; further, a sacral preauricular notch is visible on the right side (stage r/l: 2/1); remarkable attachments of gluteal muscles at the iliac bone

Stress/bone reactions: porotic hyperostosis (slight porosity at lamina externa of the parietal and occipital bones); cribra orbitalia (fine porosity on the right orbital roof); (healed) sinusitis maxillaris apparent as spicules and net-like new bone deposits in the right maxillary sinus; stomatitis (changes due to osteomyelitis?); hyperostotic new bone formation (hyperostosis frontalis and foveolae granulares) on the lamina interna of the frontal bone, generalized periostitis on the long bone surface and a local remodelled new bone apposition (haematoma) on the distal lateral part of the left femur $(20 \times 10 \mathrm{~mm})$

Trauma: polytrauma on the postcranial skeletal remains: healed fractures with callus formation visible on the distal shaft elements of both radii, slight bony surface changes but no fracture line on the right ulna (distal end damaged on the left side). Sacral bone with four different kinds of fractures: 1 . sagittal fracture line (incision) from healed fracture on the right ala ossis sacri (ala is narrower on this side); 2 . healed fracture leading horizontally from the right lateral margin to the upper border of the third sacral foramen; 3 . transversal fracture line with new bone apposition (in healing status) at level of S3 between sacral foramina; 4. continuing healed fracture in left distolateral part of the sacrum, crack at the level of third sacral foramen on the dorsal side; thickening (callus?) of the sternoclavicular part of the left clavicle and of the acromioclavicular part of the right clavicle, healed fracture of left fourth metacarpal, further, healed partial fractures of some ribs on the left dorsal arch

Degenerative changes: bilateral degeneration of the mandibular joint; distinct entheseal features on the clavicles, ribs, humeri, scapulae, radii, ulnae and phalanges; (fracture-related) arthrosis especially in the wrists; exostoses on the ischium at the location of the deep transverse perineal muscle; chronic polyarthritis at articular facets and spondylitis of cervical vertebrae 3-6, further deforming spondylosis at the lumbar vertebra bodies 2-5

Other: external layer of the right parietal bone exhibits two noteworthy, local, round, sharp-edged porous lesions which are probably of post-mortem origin; abnormal wear patterns were observed in all existing upper teeth (worn down to the dentine); numerous periapical lesions in the maxilla and mandible; severe dental calculus formation in the lower jaw; bilateral calcaneus secundarius; suspicious perforation in the dorsal-plantar direction of pinhead size in healed status of one distal phalanx (traumatic origin, feature of gout, oedema?); signs of demineralization of the bones

Anatomical variation: spondylolysis at lumbar vertebra 5 (as a result of a stress fracture in growth)

Comments: long bone measurements: left humerus $=299 \mathrm{~mm}$, left radius $=223 \mathrm{~mm}$; mature female according to WENINGER 1954, male adult according to TESCHLER-NiCOLA 1992

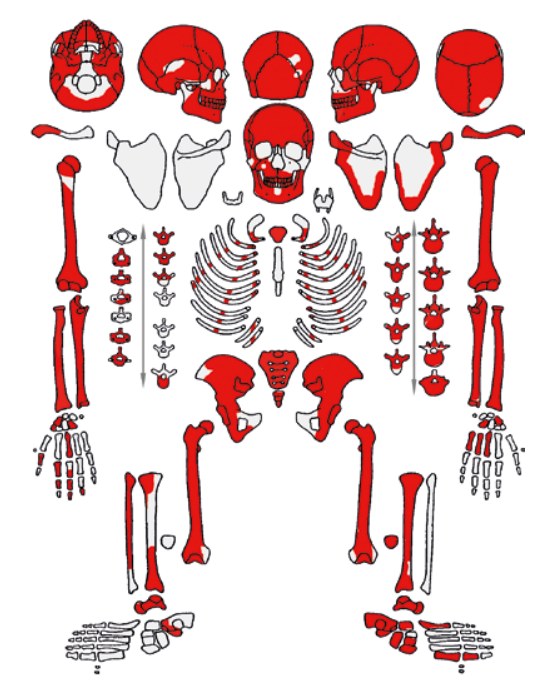


Schleinbach, Feature 59 (Group 1), NHM AA Inv. no. 27641

Sex: male, male expression of sexually dimorphic traits in the cranium (fragments) and mandible

Age: 35-45 years, dental wear (IIIc), cranial fusion of the cranial remains that are present (except of L and S4)

Body height: -

Bone surface preservation: strongly eroded

Green stains: none detected

Pelvic features: no evaluation possible

Stress/bone reactions: periosteal reactions/striations on the surface of both tibiae

Trauma: the coxarthrosis described below may be of traumatic origin

Degenerative changes: coxarthrosis - right iliac joint reveals a severe enlargement of the fossa acetabulum with distinct marginal new bone apposition and a flattened, mushroom-shaped right femoral head with exostotic new bone formation

Other: none detected

Anatomical variation: none detected

Comments: no long bone measurements possible

Comment 2: left femur of an additional individual present (7-14 years)

\section{Schleinbach, Feature 60 (multiple burial), NHM AA Inv. no. 27642}

Sex: male, male expression of sexually dimorphic traits in the cranium and pelvis as well as the robustness of postcranial elements

Age: 30-35 years, dental wear (IIc + strong uniform abrasion), ectocranial fusion (S3), sacrum (S1 fused) and symphyseal facet (stage V/VI)

TCA age: $37.7 \pm 5$ years

Body height: $168 \mathrm{~cm}$

Bone surface preservation: slightly eroded

Green stains: none detected

Pelvic features: some exostoses on the right facies auricularis (stage r/l: 2/0); right ventral pubic surface with marginal ridge (stage $\mathrm{r} / \mathrm{l}$ : 2/1); very robust pubic bones; strong muscle attachments at pubic bones and iliac crest; ridge-like exostoses at the anterior/superior border of iliac and sacral auricular facets, preauricular sulcus (shape $\mathrm{r} / \mathrm{l}: \mathrm{m}-\mathrm{m}-\mathrm{m} /---$, stage $\mathrm{r} / \mathrm{l}: 1 / 0$ ) Stress/bone reactions: remodelled periosteal reactions (striations) on the surface of lower long bones

Trauma: healed circular depression fracture in the lateral part of the left frontal bone $(15 \times$ $15 \times 10 \mathrm{~mm})$

Degenerative changes: collapsed region in the frontal part of the upper end plate of the second lumbar vertebra, possibly from disc prolapse; very strong muscle attachments with ridge like exostoses on the dorsal shaft of the tibiae (hamstrings; M. soleus - plantarflexion) Other: stomatitis on the palatine; uniform dental wear, dental chipping especially in the upper jaw, apical lesions on the upper first molars

Anatomical variation: facies poirier to the femoral head/neck; unilateral (left side) foramen parietale; lambdoid ossicles (left side); sacralization (six sacral vertebrae)

Comments: long bone measurements: right femur $=461 \mathrm{~mm}$, aDNA sample from FDI 15, TCA samples from FDI 35; remains of another middle-aged male and a 10-11-year-old child were found "near 60", but are not part of this context and are not dated
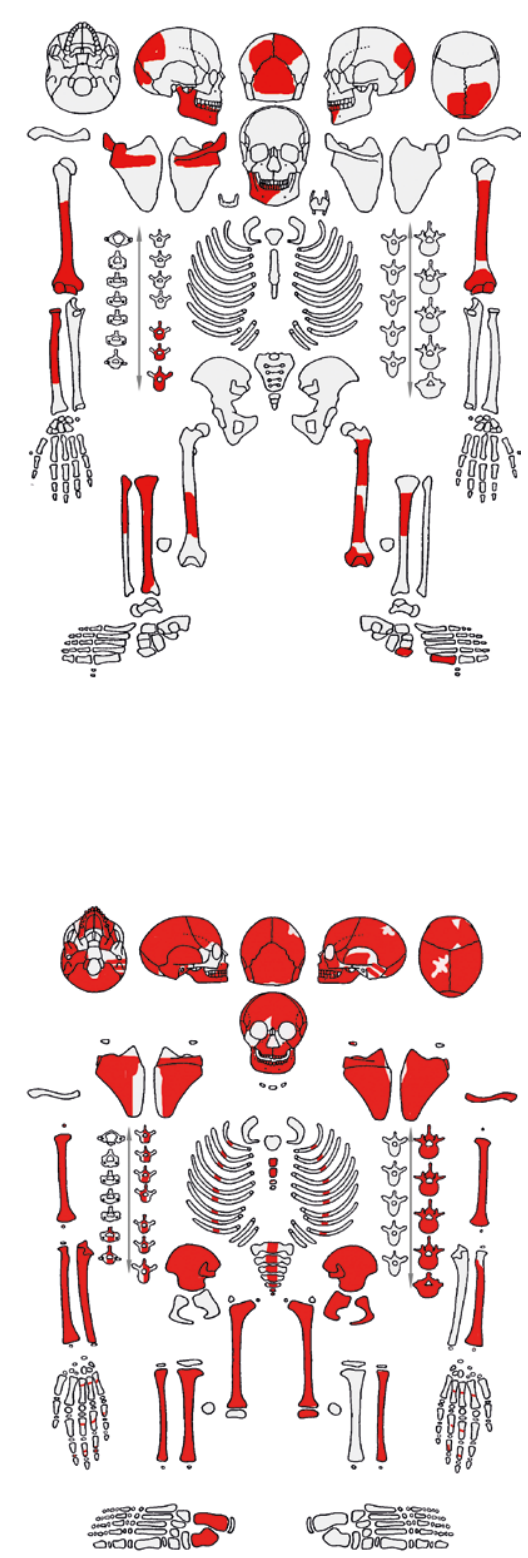


\section{Schleinbach, Feature 60A (multiple burial), NHM AA Inv. no. 27643}

Sex: male (proteomic sex identification)

Age: 8-9 years, dentition and mineralization, diaphyseal length

Body height: $120-124 \mathrm{~cm}$

Bone surface preservation: weakly eroded

Green stains: none detected

Pelvic features: ridges and exostoses on the lateral margin and inferior auricular facets (similar to 60$)$

Stress/bone reactions: fine porotic hyperostosis on the outer layer of parietal bones; stomatitis

Trauma: right talus exhibits a healed avulsion fracture of the lateral tubercle (processus posterior tali); external layer of the right parietal bone suspiciously spalled, alteration of unclear peri-/post-mortem origin

Degenerative changes: -

Other: alveolar atrophy possibly caused by strong calculus

Anatomical variation: lambdoid ossicle (left side); foramen olecrani

Comments: measurements of diaphyseal length: left ulna $=184 \mathrm{~mm}$, left femur $=292 \mathrm{~mm}$, right tibia $=233 \mathrm{~mm}$; aDNA sample taken from FDI 34

\section{Schleinbach, Feature 60B (multiple burial), NHM AA Inv. no. 27644}

Sex: female (proteomic sex identification)

Age: c. 12 years, age discrepancy between dentition (M2 nearly in masticatory plane, but persisting deciduous teeth) and measurements of diaphyseal length (indicate an age at death of 8-9 years), postcranial elements are slightly more robust than those of the child $60 \mathrm{~A}$ Body height: $115-119 \mathrm{~cm}$

Bone surface preservation: weakly eroded

Green stains: none detected

Pelvic features: -

Stress/bone reactions, trauma, degenerative changes, other: none detected

Anatomical variation: sagittal and lambdoid ossicle; bilateral trochanter tertius on femora Comments: measurements of diaphyseal length: right tibia $=230 \mathrm{~mm}$, right femur $=287 \mathrm{~mm}$, left humerus $=194 \mathrm{~mm}$, left radius $=144 \mathrm{~mm} ;$ aDNA sample taken from FDI 45

\section{Schleinbach, Feature 60C (multiple burial), NHM AA Inv. no. 27645}

Sex: female (proteomic sex identification)

Age: 3-4 years, dentition and mineralization, measurements of diaphyseal length

Body height: $75-79 \mathrm{~cm}$

Bone surface preservation: weakly eroded

Green stains: none detected

Pelvic features: -

Stress/bone reactions: bilateral cribra orbitalia (fine foramina covering the orbital roof)

Trauma: peri-/post-mortem burst fracture (nearly stellar shaped, elongated anterior-posterior in direction, $45 \times 25 \mathrm{~mm}$ ) of the left parietal bone with five radial fracture lines and chipping on the internal lamina

Degenerative changes: none detected

Other: none detected

Anatomical variation: metopic suture

Comments: measurements of diaphyseal length: femur $=145 \mathrm{~mm}$, tibia $=111 \mathrm{~mm}$, fibula $=$ $107 \mathrm{~mm} ;{ }^{14} \mathrm{C}$ and $\mathrm{C} / \mathrm{N}$ isotope samples taken from ribs, aDNA sample taken from FDI 55
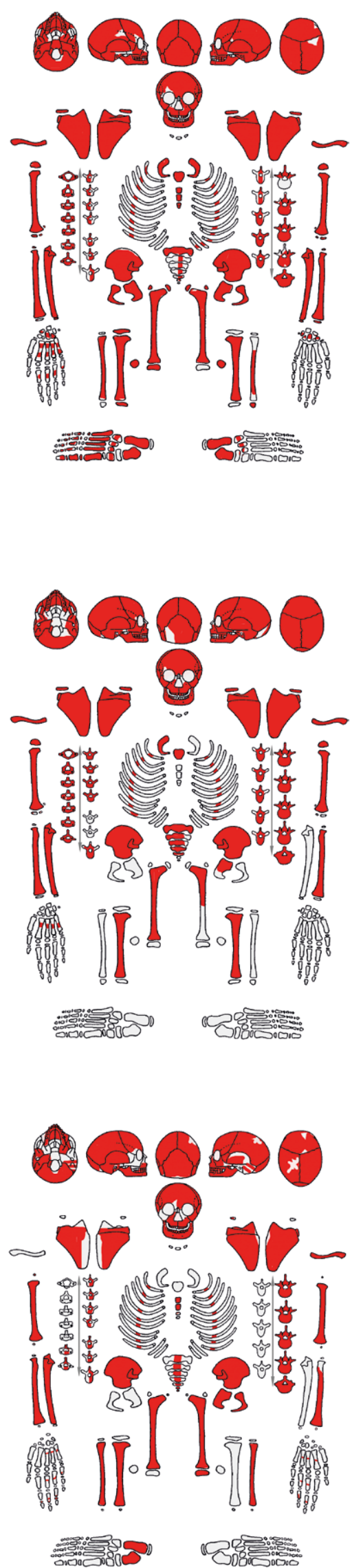
Schleinbach, Feature 63, NHM AA Inv, no. 27646

Sex: male, male expression of sexually dimorphic traits in the preserved frontal and parietal bone

Age: $20-30$ years, no fusion of cranial suture

Body height: -

Bone surface preservation: moderately eroded

Green stains: none detected

Pelvic features: -

Stress/bone reactions: fine porotic hyperostosis in the parietal bones

Trauma: none detected

Degenerative changes:-

Other: -

Anatomical variation: none detected

Comment: no long bone measurements possible, no postcranial remains present

Schleinbach, Feature 89A, NHM AA Inv. no. 27647

Sex: female, mostly female expression of sexually dimorphic traits in the cranium

Age: 30-45 years, severe dental wear, fusion of cranial sutures (S3, C2/C3 fused)

Body height: -

Bone surface preservation: cranium moderately eroded; no postcranial remains (except of some cervical vertebra and rib fragments)

Green stains: right side of temporal, parietal and occipital bone, maxilla and zygomatic bone; further, skull base and all present cervical vertebrae

Pelvic features: -

Stress/bone reactions: internal layer of frontal and parietal bones reveals foveolae granulares (pits on the inner surface of the skull caused by arachnoid granulations), and a cystic lesion on the left parietal; active sinusitis maxillaris on the right side with inflammatory reactions (fine remodelled new bone formation); severe stomatitis (distinct ridge-like exostoses in the palatine)

Trauma: none detected

Degenerative changes: strong changes of the left mandibular joint with enlarged facets Other: both alveoli of maxillary M3 in healing status; general severe dental wear in the upper jaw, apical lesions on both first molars; alveolar atrophy and alveolar pitting

Anatomical variation: metopic suture; some lambdoid ossicles

Comments: no long bone measurements possible (no postcranial remains present except for the cervical vertebrae); buried with individual 89B, settlement burial

\section{Schleinbach, Feature 89B, NHM AA Inv. no. 27648}

Sex: male, male expression of sexually dimorphic traits in the cranium, mandible and pelvis Age: 25-30 years, fusion of cranial suture (S3 fused), dental wear (IIb), clavicle (stage III) and sacral vertebrae (S1/S2 fusing)

Body height: -

Bone surface preservation: moderately eroded

Green stains: right parietal, temporal and occipital bones, both zygomatic processes, right side of the mandible, cervical vertebrae $\mathrm{vC5} / 6 / 7$, thoracic vertebra vTh1, right clavicle and scapula, some metacarpals and phalanges of the right hand

Pelvic features: right preauricular sulcus is smooth and wide (maybe in context with the spondylolysis of fifth lumbar vertebra); preauricular sulcus (shape $\mathrm{r} / \mathrm{l}: \mathrm{i}-\mathrm{m}-\mathrm{m} / \mathrm{m}-\mathrm{m}-\mathrm{m}$, stage $\mathrm{r} / \mathrm{l}: 2 / 1)$

Stress/bone reactions: stomatitis visible as fine porosity in the palatine

Trauma: none detected

Degenerative changes: none detected

Other: deep fovea granulares (pits) in the inner layer of parietal bones running parallel to the sagittal suture; caries lesions in the mandibular M2; spondylolysis (isolated arch) of the vL5 Anatomical variation: very long transversal process in the second lumbar vertebra Comment: no long bone measurements possible; buried with individual 89A, settlement burial
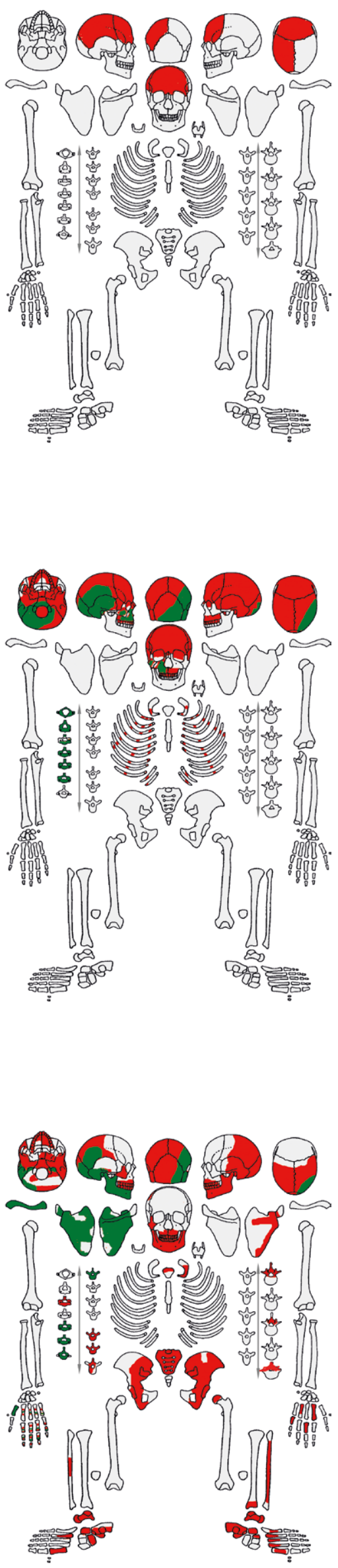
Schleinbach, Feature 90, NHM AA Inv. no. 27649

Sex: female, female expression of sexually dimorphic traits in the pelvis

Age: 27-35 years, dental wear (IIb), pubic symphysis (V-VI), clavicle (> III), sacral vertebra (S1 fused)

\section{Body height: $154 \mathrm{~cm}$}

Bone surface preservation: moderately to strongly eroded

Green stains: thoracic vertebrae, carpal and metacarpal bones of the right hand

Pelvic features: preauricular sulcus is very large, wide and deep (shape $r / \mathrm{l}$ : $\mathrm{f}-\mathrm{f}-\mathrm{f} / \mathrm{f}-\mathrm{f}-\mathrm{f}$, stage r/l: 4/4); marked ridges at the attachment area of M. obliquus externus and internus; ridgelike structures in the anterior and superior part of the sacroiliac joint (stage r/l: 2/2); some exostoses visible on the surface of the sacral auricular facet and area of sacroiliac ligaments; sacral preauricular notch (bone loss) $(5 \times 10 \mathrm{~mm}$ ) visible at the right ventrosuperior margin of the ala ossis sacri (stage r/l: 2/1); left pectineal line of pubis shows a small extended tuberculum pubis (pyramidal exostosis, stage $\mathrm{r} / \mathrm{l}: 0 / 2$ ); left dorsal pubic surface reveals pubic pitting (small chain like imprints, stage r/l: 1/2); strongly developed exostoses (stage r/l: 2/2) and lesions (stage $\mathrm{r} / \mathrm{l}: 2 / 2$ ) on the ventral pubic surfaces

Stress/bone reactions: lumbar vertebrae vL5 and vS1 exhibit osteophytes and inflammatory reactions on the ventral side of the body (possible lumbar disc herniation)

Trauma: see above

Degenerative changes: strong attachments of the M. teres minor and M. brachialis (flexion) at both humeri; sternal part of the left clavicle seems enlarged due to strong entheseal attachment

Other: there are two alveolar sockets at the position of the right first incisor (either persisting deciduous first incisor or the permanent incisor had two roots)

Anatomical variation: ossific bridging at the right side of the scapula over the scapular notch; foramen olecrani on the left distal humerus

Comments: long bone measurements reveal length differences (right/left side): femur = $397 / 409 \mathrm{~mm}$; tibia $=347 / 350 \mathrm{~mm}$

\section{Schleinbach, Feature 91, NHM AA Inv. no. 27650}

\section{Sex: undetermined}

Age: 3-5 years (size comparison of frontal bone with a child from Gars/Thunau NHM Inv. no. 25062)

Body height: -

Bone surface preservation: moderately eroded (only frontal bone preserved)

Green stains: none detected

Pelvic features: -

Stress/bone reactions: cribra orbitalia (left orbital roof covered by fine porosity)

Trauma: none detected

Degenerative changes: -

Other: none detected

Anatomical variation: none detected

Comments: no postcranial remains, femur fragments (left side) and vC2 of an additional adult individual
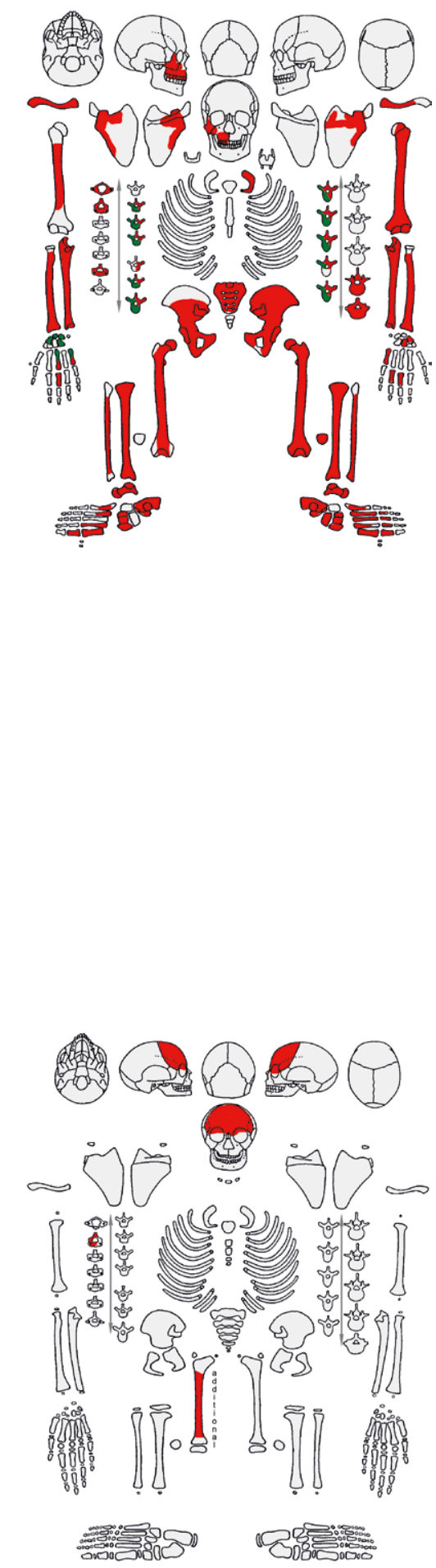
Schleinbach, Feature 101/1 (Group 2), NHM AA Inv. no. 27651

Sex: undetermined

Age: 14-16 years, no cranial suture fusion, dental development (lower second molar not fully developed) and status of epiphyseal fusion (open: cranial base, proximal right humerus, proximal left femur and tuber ischiadicum)

Body height: -

Bone surface preservation: moderately eroded

Green stains: occipital bone, skull base, mandible (right side) and second cervical vertebra Pelvic features: preauricular sulcus region (shape r/l: i-i-f/---, stage r/l: 1/0)

Stress/bone reactions: none detected

Trauma: none detected

Degenerative changes, other, anatomical variation:-

Comments: no measurements possible

Comment 2: commingled skeletal remains 101/1,101/2 and 101/3

Schleinbach, Feature 101/2 (Group 2), NHM AA Inv. no. 27652

Sex: undetermined (female?), postcranial remains are very gracile, no other sexing characteristics available

Age: $20-60$ years, cranial fusion of lambda suture nearly finished

Body height: -

Bone surface preservation: moderately eroded

Green stains: none detected

Pelvic features:-

Stress/bone reactions: fine porosity in the external layer of parietal bone (porotic hyperostosis); new bone apposition in the sagittal sinus (perisinusitis)

Trauma: none detected

Degenerative changes: none detected

Other:-

Anatomical variation: lambdoid suture very irregular

Comments: no measurements possible, commingled skeletal remains 101/1, 101/2 and $101 / 3$

\section{Schleinbach, Feature 101/3 (Group 2), NHM AA Inv. no. 27653}

Sex: undetermined (male?), only very robust right femur present

Age: $20-60$ years

Body height: -

Bone surface preservation: moderately eroded

Green stains:-

Pelvic features:-

Stress/bone reactions: none detected

Trauma: none detected

Degenerative changes: none detected

Other:-

Anatomical variation:-

Comments: no measurements possible, commingled skeletal remains 101/1, 101/2 and $101 / 3$
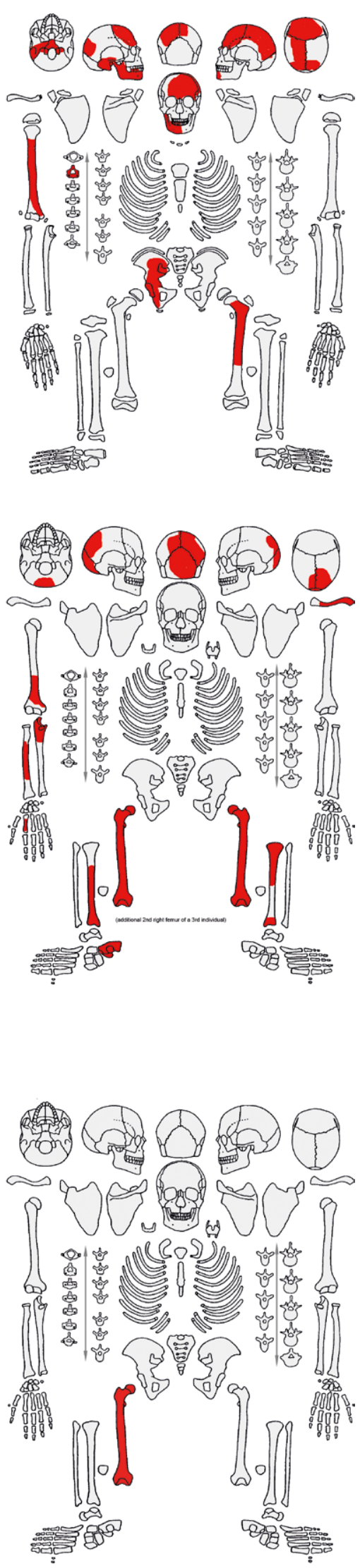


\section{Schleinbach, Feature 102 (Group 2), NHM AA Inv. no. 27655}

Sex: male, male expression of sexually dimorphic traits in the cranium and mandible Age: 25-30 years, dental wear (IIa) and cranial suture fusion $(<30)$

Body height: $174 \mathrm{~cm}$ (BREITINGER 1937)

Bone surface preservation: moderately eroded

Green stains: none detected

Pelvic features:-

Stress/bone reactions: none detected

Trauma: probably peri-mortem sharp force polytrauma to the cranium: right parietal bone reveals a horizontally trending crack, originating from the bregma and laterally arch-shaped (antero-posterior direction, $100 \times 130 \mathrm{~mm}$ ) directing to the lambda (mid-point of lambdoidal suture); left parietal bone, near the coronal suture, shows a bevelled edge margin; left orbital margin of the frontal bone reveals a triangularly shaped spalling; fracture patterns are present in several other cranial fragments from the parietal/occipital bones

Degenerative changes: none detected

Other: internal layer of frontal and temporal bone exhibits several cone-shaped hyperostoses

Anatomical variation: none detected

Comments: long bone measurements: left tibia $=393 \mathrm{~mm}$

\section{Schleinbach, Feature 103/1 (Group 2), NHM AA Inv. no. 27656}

Sex: male, male expression of observable sexually dimorphic traits in the cranium and mandible

Age: 25-35 years, no cranial fusion of the present coronal suture, dental wear (IIb)

Body height: -

Bone surface preservation: moderately eroded

Green stains: none detected

Pelvic features:-

Stress/bone reactions, trauma, degenerative changes, other, anatomical variation: none detected

Comments: no long bone measurements possible; total grave content 103: cranial remains (ossa frontalia) of 2 adult male individuals (103/1,103/2), additional fragmented postcranial elements of 2 or 3 individuals (femora and humerus of a male individual (possibly 103/1), left femur and left tibia of a 14-20-year-old (103/3) and left iliac bone of a female (103/4), left scapula, proximal humerus and phalanges of the right hand of an adult (103B)

\section{Schleinbach, Feature 103/2 (Group 2), NHM AA Inv. no. 27657}

Sex: male, male expression of sexually dimorphic traits in the cranium

Age: $\mathbf{2 0 - 4 0}$ years, no cranial fusion of the present coronal suture

Body height: -

Bone surface preservation: strongly eroded

Green stains: none detected

Pelvic features, stress/bone reactions, trauma, degenerative changes, other, anatomical variation:-

Comments: no long bone measurements possible
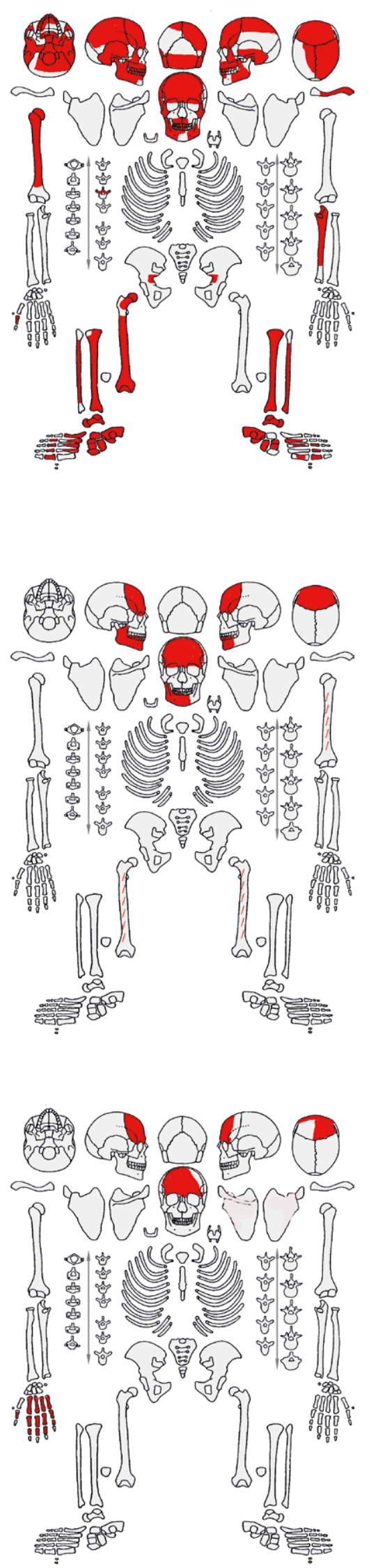


\section{Schleinbach, Feature 103/3 (Group 2), NHM AA Inv. no. 27658}

\section{Sex: undetermined}

Age: 14-20 years, epiphyseal fusion not finished in the proximal tibia and distal femur

Body height: -

Bone surface preservation: strongly eroded

Green stains: distal shaft of the left femur

Pelvic features: -

Stress/bone reactions, trauma, degenerative changes, other, anatomical variation: none detected

Comments: no measurements possible
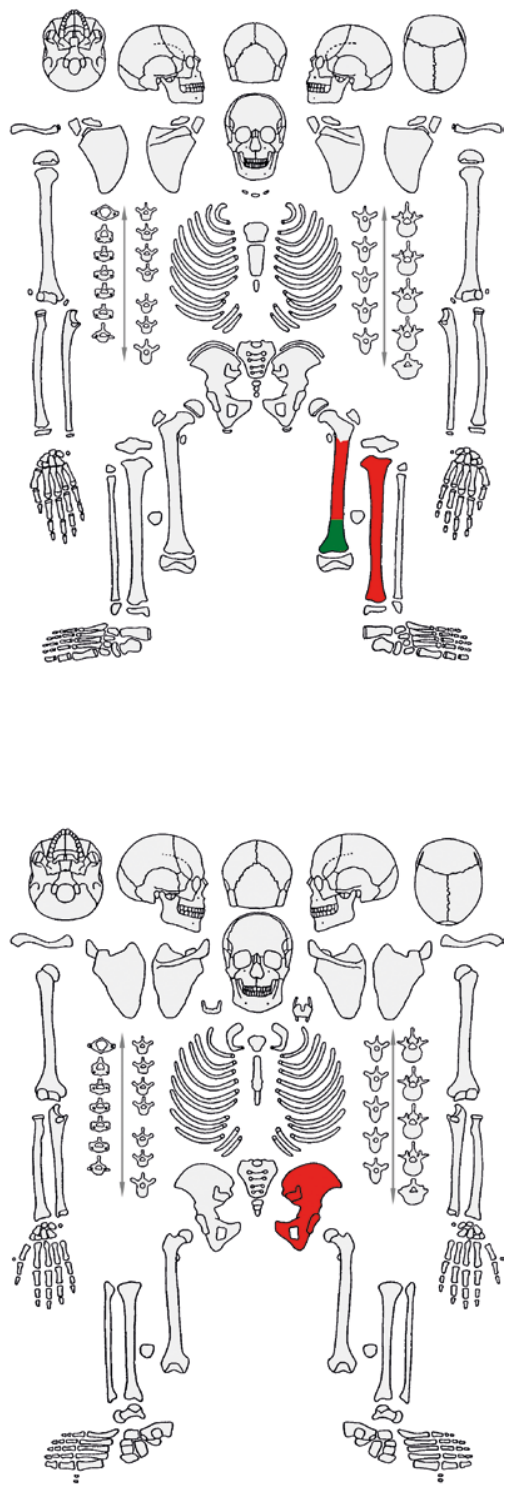

Schleinbach, Feature 103/4 (Group 2), NHM AA Inv. no. 27679

Sex: female, pelvic characteristics are clearly female, os ilium preauricular sulcus -1 , incisura ischiadica -2 , arc compose -2

Age: $20-40$ years (no degenerative changes at acetabulum)

Body height: -

Bone surface preservation: strongly eroded

Green stains: -

Pelvic features: preauricular sulcus (shape i-i-i, stage 2)

Stress/bone reactions, trauma, degenerative changes, other, anatomical variation: none detected

Comments: partial left os ilium, no measurements possible
Schleinbach, Feature 103B (Group 2), NHM AA Inv. no. 27654

\section{Sex: undetermined}

Age: $20-40$ years, epiphyseal fusion finished, no degenerative changes

Comments: in situ documented left scapula, proximal humerus and phalanges of the right hand 


\section{Schleinbach, Feature 104/1 (Group 2), NHM AA Inv. no. 27659}

Sex: female, female expression of sexually dimorphic traits in the cranium, mandible and pelvis

Age: $\mathbf{3 0}-\mathbf{3 5}$ years, dental wear (IIb), clavicle (> 30)

Body height: $152 \mathrm{~cm}$

Bone surface preservation: moderately eroded

Green stains: temporal bones, right side of maxilla (plus teeth) and mandible, all cervical vertebrae, acromial parts of clavicles and scapulae, left caput humeri, several ribs of the left side Pelvic features: left preauricular sulcus is a deep depression with closed circumference (shape r/l: ---/f-f-f-, stage r/l: 0/4); furthermore, a sharp margin is developed at the upper medial part of the left sacroiliac joint (stage $\mathrm{r} / \mathrm{l}: \mathrm{0} / 2$ )

Stress/bone reactions: none detected

Trauma: development of distinct osteophytes located at the base plate of the fifth lumbar vertebra (vL5) and cover plate of the first sacral vertebra (S1, possibly caused by a compression trauma and/or by a spondylolysis of vL5)

Degenerative changes: left calcaneus reveals distinct osteophytes at the cuboid articular facet

Other: small caries lesion at the interface of the maxillary right canine $(\mathrm{C})$ and the first premolar (PM1), calcaneus secundarius on the anterior articular facet of the right calcaneus Anatomical variation: none detected

Comments: long bone measurements: right humerus $=282 \mathrm{~mm}$, left ulna $=245 \mathrm{~mm}$, right femur $=404 \mathrm{~mm}$, right fibula $=324 \mathrm{~mm} ;{ }^{14} \mathrm{C}$ and $\mathrm{C} / \mathrm{N}$ isotope samples taken from ribs; bones of additional individuals: humerus of a foetus (104/2, see below), left pelvis of a 35-45-year-old male (104/3, facet stage of the symphysis 7/8)

\section{Schleinbach, Feature 104/2, NHM AA Inv. no. 27660}

Sex: undetermined

Age: 7-8 lunar months, foetus, diaphyseal length of the right humerus (c. $43 \mathrm{~mm}$ )

Body height: -

Bone surface preservation: slightly eroded (only humerus preserved)

Green stains, pelvic features, stress/bone reactions, trauma, degenerative changes, anatomical variation: -

Comment: found with 104/1
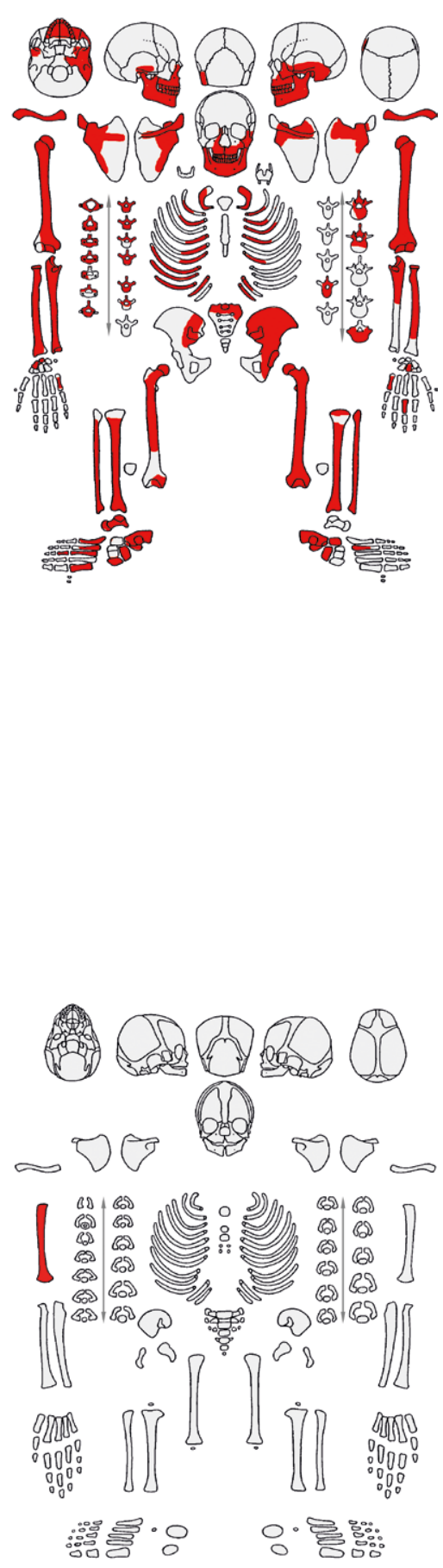
Schleinbach, Feature 105 (Group 2), NHM AA Inv. no. 27662

\section{Sex: undetermined}

Age: 3-4 years, status of dentition

Body height: -

Bone surface preservation: moderately eroded

Green stains: mandible fragment, cervical and thoracic vertebra, several ribs

Pelvic features: -

Stress/bone reactions: perisinusitis (internal layer of occipital bone with net-like new bone deposition at the confluens sinuum and sinus transversus); possible scurvy: distinct periostitis characterized by widespread new bone apposition on the lateral shaft of the left femur and the medial part of the left tibia; pleuritis (some ribs show fine porotic new bone formation on the internal dorsal part)

Trauma, degenerative changes, other, anatomical variation: none detected

Comments: no measurements of diaphyseal length possible, $\mathrm{C} / \mathrm{N}$ isotope sample taken from rib

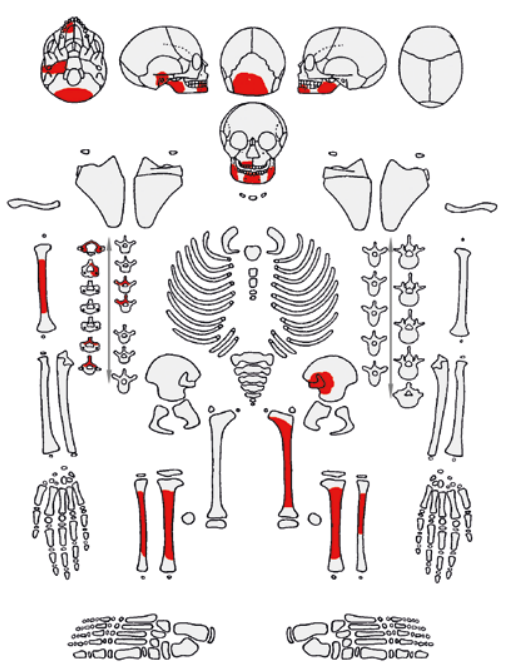

Schleinbach, Feature 106/1 (Group 2), NHM AA Inv. no. 27663

Sex: female, female expression of sexually dimorphic traits in the cranium and pelvis Age: 16-20 years, open sagittal/occipital sutures, cranial base (sphenobasilar joint), pars basilaris and lateralis of occipital bone, clavicle, tuber of the ischium and S1 (sacrum) suggest the individual is 14-18 years old; the remaining epiphyseal fusion is completed, which points to a higher age (20-22 years)

Body height: $153 \mathrm{~cm}$

Bone surface preservation: moderately eroded

Green stains: none detected

Pelvic features: well-defined preauricular sulcus with closed circumference (shape $r / l$ : f-f-/f-f-f, stage r/l: 3/3); sacral preauricular notch at ventrosuperior margin of right ala ossis sacri, probably corresponding recess (small depression) on right side of iliac auricular facet (stage r/l: 2/1); spina bifida occulta visible as incomplete closure of sacral vertebral arches four and five

Stress/bone reactions: bilaterally developed localized new bone deposition on the dorsal distal part (facies poplitea) of the femora; healed periostitis in the form of bony striations present in the medial shaft of both tibiae; partly remodelled fine porotic new bone apposition on the pleural side of some left ribs indicative for pleuritis (in healing status)

Trauma: none detected

Degenerative changes: slight hyperostotic bone growth in the proximal part of the caput tali Other: bilaterally developed distinct attachment of the deltoid and brachial muscles to the humeri

Anatomical variation: bilateral foramen olecranon; ossicle at bregma

Comments: long bone measurements: right humerus $=285 \mathrm{~mm}$, right ulna $=242 \mathrm{~mm}$, left femur $=408 \mathrm{~mm}$, left tibia $=342 \mathrm{~mm}$

Schleinbach, Feature 106/2 (Group 2), NHM AA Inv. no. 27664 Sex: undetermined, no sexually dimorphic characters present Age: $20-40$ years

Body height: -

Bone surface preservation: strongly eroded

Green stains: lumbar vertebrae and several phalanges of the hand

Pelvic features, stress/bone reactions, trauma, degenerative changes, other, anatomical variation: -

Comments: no long bone measurements possible
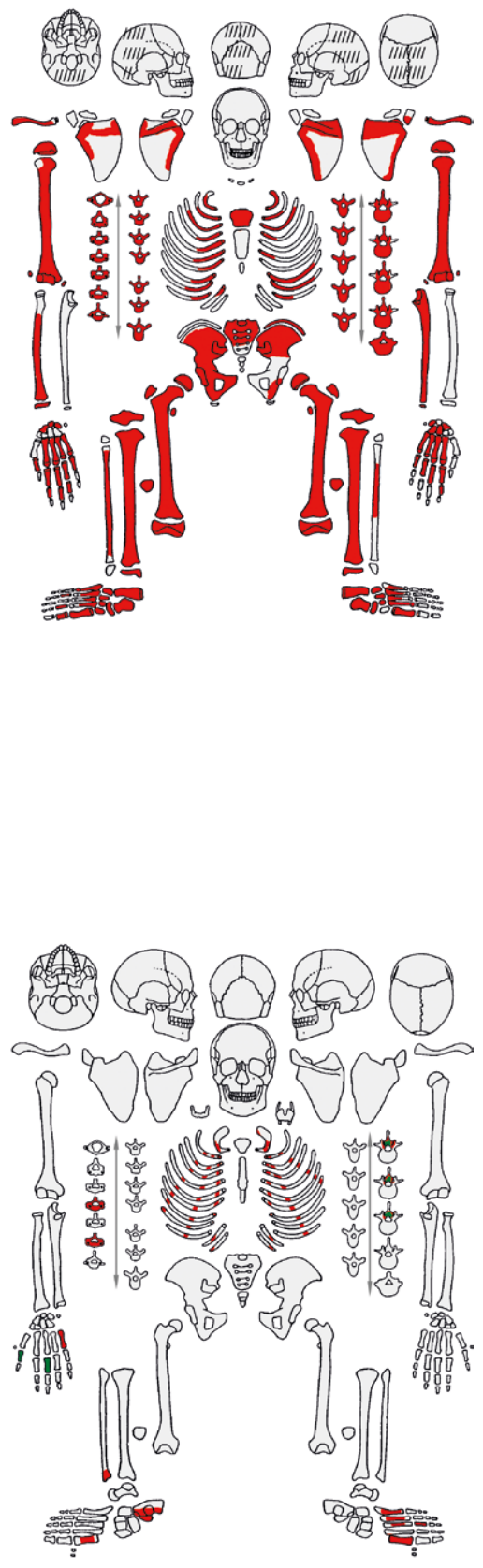


\section{Schleinbach, Feature 107 (Group 2), NHM AA Inv. no. 27665}

Sex: female, female expression of the sexually dimorphic traits of the mandible and in the preserved fragments of the right iliac bone

Age: $40-60$ years, intravital tooth loss in the mandible; postcranial degenerative changes indicate an elderly individual

Body height: -

Bone surface preservation: moderately eroded

Green stains: right ramus mandibulae, third cervical vertebra, first thoracic vertebra, first lumbar vertebra, right clavicle, right scapula, several ribs

Pelvic features: fragments of preauricular region have female characteristics (sulcus preauricularis shape $\mathrm{r} / \mathrm{l}$ : $\mathrm{f---/---,} \mathrm{stage} \mathrm{r} / \mathrm{l}: 2 / 0$ )

Stress/bone reactions: none detected

Trauma: polytrauma at postcranium, 1. well-healed fracture (with callus) of the left distal ulnar shaft; 2. mid-shaft of left clavicle exhibits a healed fracture in an angular position; 3. distinct and widespread new bone deposition on the ventral and dorsal aspect of right scapula fragment; 4. ossified haematoma on the mediodistal shaft of the right fibula

Degenerative changes: distinct changes in the second cervical vertebra ( $\mathrm{vC} 2$ - dens axis) and femoral head (stage 2/3)

Other: intravital tooth loss in the mandible along with alveolar atrophy; strong attachments at the left humerus (M. pectoralis major) and at the left femur muscles for hip flexion (external obturator, gluteal, iliac and pectineal muscles, adductor muscles)

Anatomical variation: bony bridge over supra-scapular incisura (suprascapular foramen) Comment: no long bone measurements possible

\section{Schleinbach, Feature 108 (Group 2), NHM AA Inv. no. 27666}

Sex: male, male expression of sexually dimorphic traits of the pelvis and distinctly male robustness of long bones

Age: 30-40 years, epiphyseal fusion finished, clavicle (> stage III), slight degenerative changes

Body height: $169 \mathrm{~cm}$ (BREITINGER 1937)

Bone surface preservation: moderately eroded (only postcranial remains)

Green stains: none detected

Pelvic features: preauricular sulcus (shape r/l: $\mathrm{m}-\mathrm{m}-/---$, stage $\mathrm{r} / \mathrm{l}: 1 / 0$ ); smooth exostoses at the antero-superior margin of the right iliac auricular facet (stage $\mathrm{r} / \mathrm{l}: 2 / 0$ )

Stress/bone reactions: acute and healed new bone formation at the rib-vertebral joints from pleuritis (starting from the first rib, in healing status)

Trauma: remodelled local haematoma $(\mathrm{c} .10 \times 10 \mathrm{~mm})$ on the right tibia

Degenerative changes: none detected

Other: multifocal lytic lesions of spine: $2^{\text {nd }}-7^{\text {th }}$ cervical vertebrae and $1^{\text {st }}-6^{\text {th }}$ thoracic vertebrae; medial mid-shaft of the right tibia exhibits a slight thickening with striations (haematoma)

Anatomical variation: none detected

Comment: long bone measurements: right femur $=445 \mathrm{~mm}$, right tibia $=377 \mathrm{~mm}$
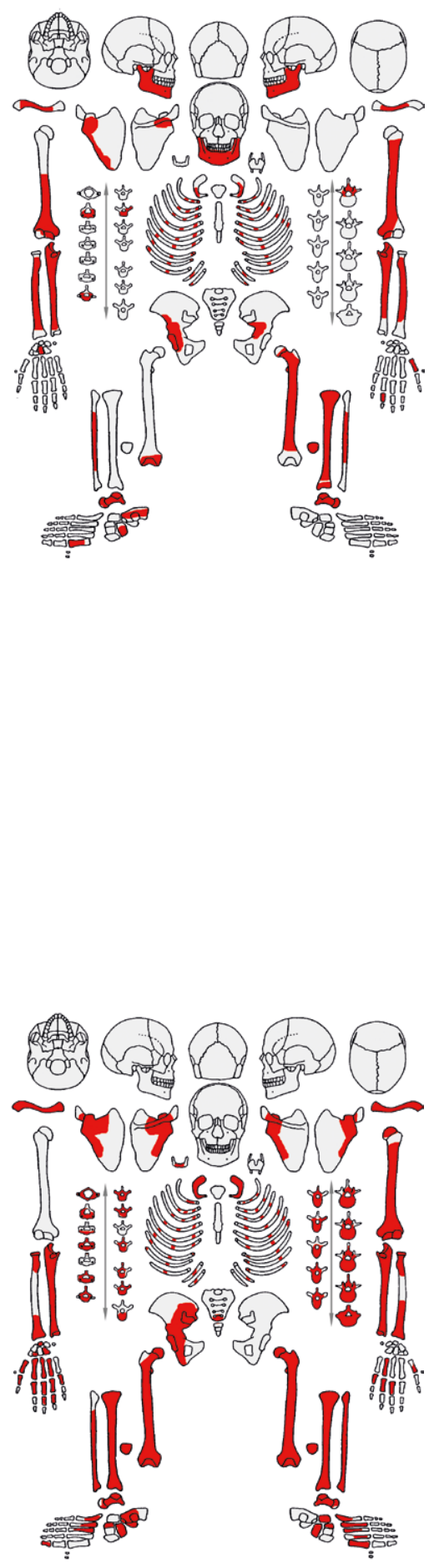
Schleinbach, Feature 109/1 (Group 2), NHM AA Inv. no. 27667

Sex: male, male expression of sexually dimorphic traits in the pelvis, but robustness $(-1)$ of long bones

Age: $30-40$ years, clavicle (> stage III), slight degenerative alterations

Body height: $161 \mathrm{~cm}$

Bone surface preservation: moderately eroded (postcranial remains only)

Green stains: none detected

Pelvic features: ridge-like muscle attachment of the gluteal muscles bilaterally developed at iliac bones; preauricular sulcus of male characteristic (shape $\mathrm{r} / \mathrm{l}: \mathrm{m}-\mathrm{m}-\mathrm{m} / \mathrm{m}-\mathrm{m}-\mathrm{m}$, stage $\mathrm{r} / \mathrm{l}: 1 / 1)$

Stress/bone reactions: pleuritis (partially remodelled new bone deposition on the pleural side of some left ribs, in healing condition)

Trauma: none detected

Degenerative changes: slight changes at major joints

Other: remodelled localized haematoma on the dorsal tubercle of the right radius (c. $1 \times$ $1 \mathrm{~cm}$ ) and the distal lateral portion of the left tibia $(\mathrm{c} .2 \times 2 \mathrm{~cm})$

Anatomical variation: none detected

Comments: long bone measurements: left radius $=251 \mathrm{~mm}$, left ulna $=273 \mathrm{~mm}$, left femur $=434 \mathrm{~mm}$; cranial remains of child 109/2 found south of 109/1

\section{Schleinbach, Feature 109/2, NHM AA Inv. no. 27668}

\section{Sex: undetermined}

Age: 2-3 years (by comparison of cervical vertebra C1, petrous parts and parietal bones with Schleinbach, Feature 105)

Body height: -

Bone surface preservation: strongly eroded (cranial and three rib fragments)

Green stains: none detected

Pelvic features, stress/bone reactions, trauma, degenerative changes, other, anatomical variation: -

Comments: no measurements possible, ${ }^{14} \mathrm{C}$ and $\mathrm{C} / \mathrm{N}$ isotope samples taken from rib

\section{Schleinbach, Feature 110 (pit), NHM AA Inv. no. 27669}

Sex: female?, shape of ischiopubic ramus (fragment), gracility of bone fragments

Age: $20-40$ years, epiphyseal fusion finished, no degenerative changes visible at joint facet of proximal tibia, talus, phalanges and vertebral joints

Body height: -

Bone surface preservation: moderately eroded (fragmentary postcranial remains)

Green stains: fragments of vertebral arches and ribs

Pelvic features:-

Stress/bone reactions: none detected

Trauma: none detected

Degenerative changes:-

Other: spondylolysis (vertebral arch and body not fused), visible in two isolated vertebral arches (probably from lumbar vertebrae three and four)

Anatomical variation: none detected

Comments: no long bone measurements possible
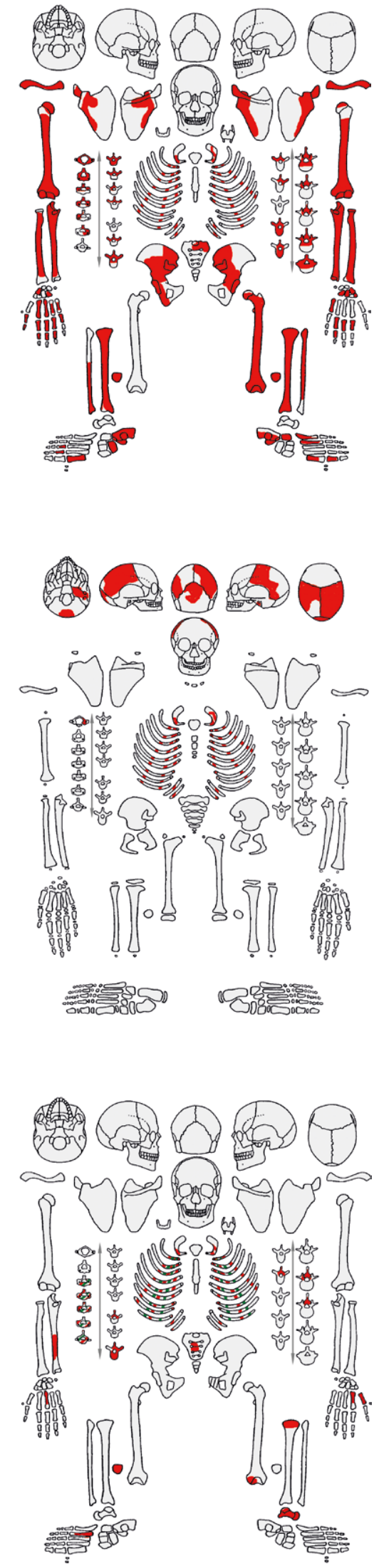


\section{Schleinbach, Feature 111 (Group 2), NHM AA Inv. no. 27670}

Sex: undetermined

Age: 7-9 years, status of dentition and diaphyseal length (right femur)

Body height: $100-105 \mathrm{~cm}$

Bone surface preservation: moderately eroded

Green stains: none detected

Pelvic features: none detected

Stress/bone reactions: probably acute pleuritis visible as fine porotic new bone deposition bilaterally and dorsally on the internal side of some ribs

Trauma: possible (greenstick) fracture in the mediosuperior shaft of the left femur, a thickening is visible

Degenerative changes: -

Other: mandible exhibits distinct features

Anatomical variation: none detected

Comments: measurement of the right femur: diaphyseal length $=230 \mathrm{~mm}$, additional right maxilla of an early adult individual (dental wear $\mathrm{Ib}=\mathrm{c} .20$ years, no pathological conditions)

\section{Schleinbach, Feature 112 (Group 2), NHM AA Inv. no. 27671}

Sex: female?, only two observable sexually dimorphic traits in the frontal bone (-1) available, gracility of long bone fragments

Age: 15-21 years, no fusion of cranial suture and iliac crest, but finished epiphyseal fusion in scapula, phalanges (hand and foot), distal tibia

Body height: -

Bone surface preservation: moderately eroded

Green stains: left scapula and ribs

Pelvic features: -

Stress/bone reactions, trauma, degenerative changes, other, anatomical variation: none detected

Comments: no long bone measurements possible; additional animal bones
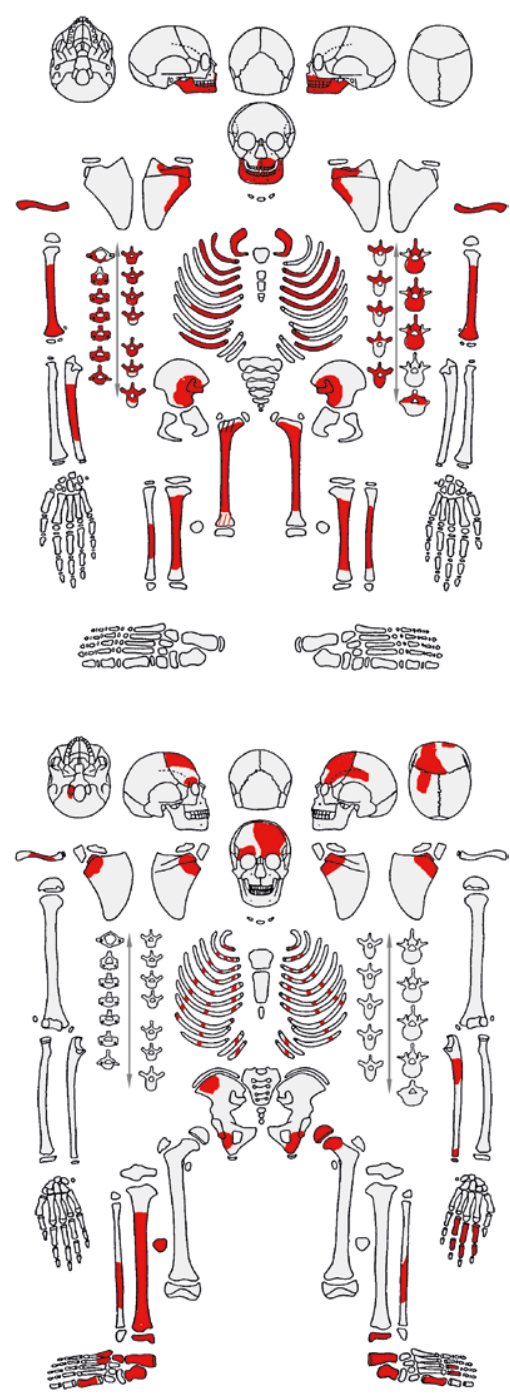

\section{Schleinbach, Feature 113}

Sex:-

Age: -

Comment: no human remains preserved. Bone of a destroyed grave found together with a handled cup at a depth of $30 \mathrm{~cm}$ (RETTENBacher 2004, 101) 


\section{Schleinbach, Feature 114, NHM AA Inv. no. 27672}

Sex: male?, high robustness of lower limbs and strong muscle attachments

Age: 20-40 years, epiphyseal fusion finished, slight degenerative changes

Body height: $170 \mathrm{~cm}$

Bone surface preservation: moderately eroded (lower limb only)

Green stains: none detected

Pelvic features: -

Stress/bone reactions: none detected

Trauma: none detected

Degenerative changes: slight changes

Other: none detected

Anatomical variation: none detected

Comments: long bone measurements: right tibia $=383 \mathrm{~mm}$; additional vertebral body and metacarpal of a child
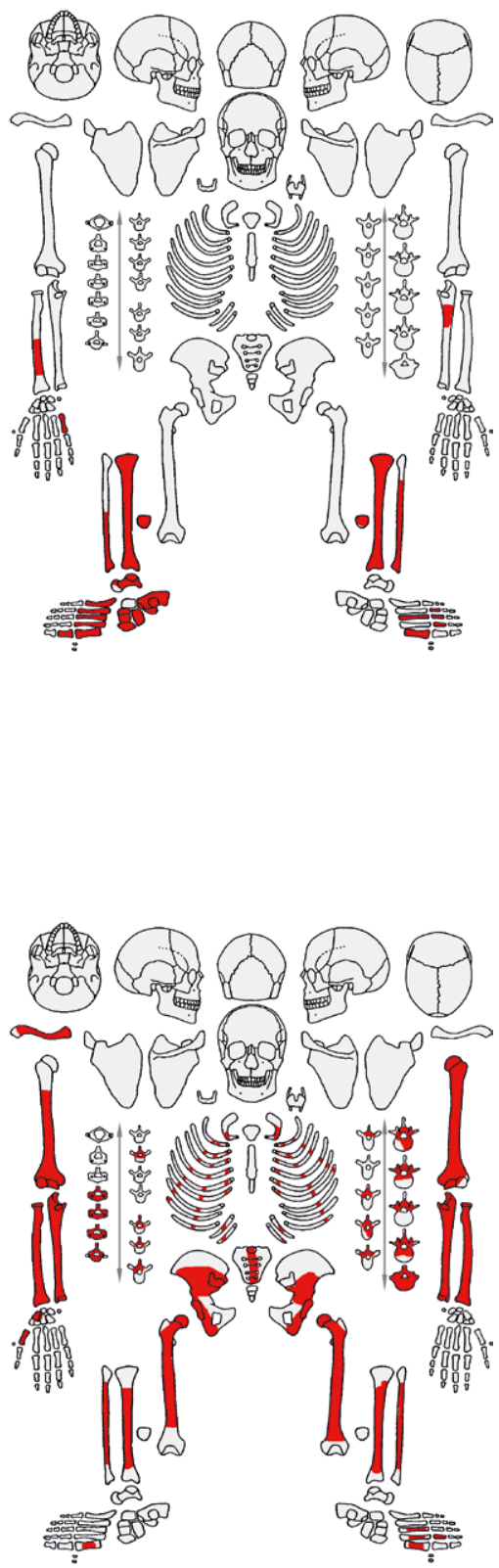

\section{Schleinbach, Feature 115, NHM AA Inv. no. 27673}

Sex: male, male expression of sexually dimorphic traits of the pelvis and the robustness of long bones

Age: 30-40 years, epiphyseal fusion finished, clavicle (> stage III), slight degenerative changes

Body height: -

Bone surface preservation: moderately eroded (postcranial skeletal remains only)

Green stains: none detected, but the surface of the left humerus, ulna and radius is largely covered with greyish discolouration

Pelvic features: preauricular sulcus (shape r/l: m-m-/m-m-, stage r/l: 1/1)

Stress/bone reactions: bilateral remodelled new bone apposition in the dorsal part of four ribs (pleuritic); cortical bone of both femora and tibiae exhibit thickening and strong porosity, this condition could be related to osteitis or osteomyelitis (potentially a secondary infection, spreading from the primary infection - fracture in the distal part of the left radius - via the bloodstream)

Trauma: severe fracture of the left wrist: left radius end shows thickening and osteoarthritic changes, fractured os lunatum merged with radius, healed in malposition

Degenerative changes: slight changes in major joints

Other: none detected

Anatomical variation: bilateral foramen olecrani

Comments: long bone measurements: left humerus $347 \mathrm{~mm}$, right radius $=264 \mathrm{~mm}$, right ulna $=288 \mathrm{~mm}$ 
Schleinbach, Feature 1927/1, NHM AA Inv. no. 27675

Sex: female, female expression of sexually dimorphic traits in the cranium, mandible and pelvis, and gracility of long bones

Age: 18-21 years, cranial sutures open, dental wear (Ia) and epiphyseal fusion finished, symphysis (stage I/II)

Body height: -

Bone surface preservation: moderately eroded

Green stains: none detected

Pelvic features: 2 depression pits on the preauricular sulcus of the right side; the left side exhibits a small but long sulcus with small tubercle (shape $r / l: f-f-f / f-f-m$, stage $r / l: 3 / 2$ ); spina ischiadica of the right side is particularly pronounced; right sacral side has a well-defined impression at the margo auricularis (stage $\mathrm{r} / \mathrm{l}$ : 2/1); right pars lateralis of the sacrum has a small but well defined sacral preauricular extension $(12.5 \times 5 \mathrm{~mm}$, stage $\mathrm{r} / \mathrm{l}: 2 / 0)$, with a corresponding facet at the iliac auricular facet; right iliac auricular facet reveals fine porosity from an inflammation (stage $r / 1: 2 / 0$ )

Stress/bone reactions: none detected

Trauma: peri-/post-mortem sharp cut (c. $12 \mathrm{~mm}$ long) visible at the proximal condyles of the left tibia, furthermore, the right frontal and parietal bone exhibit two peri-/post-mortem oval sharp blows (c. $18 \times 27 \mathrm{~mm}$, c. $25 \times 33 \mathrm{~mm}$ )

Degenerative changes: none detected

Other: none detected

Anatomical variation:-

Comments: no long bone measurements possible; ${ }^{14} \mathrm{C}$ and $\mathrm{C} / \mathrm{N}$ samples taken from femur; feature contains commingled skeletal remains of four individuals

\section{Schleinbach, Feature 1927/2, NHM AA Inv. no. 27676}

Sex: male, male expression of sexually dimorphic traits in the mandible and pelvis, and robustness of the long bones

Age: 40-50 years, severe oblique dental wear (IIIc/IVa), epiphyseal fusion finished, symphysis (stage VIII/IX)

Body height: -

Bone surface preservation: slightly eroded

Green stains: none detected

Pelvic features: preauricular sulcus (shape $\mathrm{r} / \mathrm{l}: \mathrm{m}-\mathrm{m}-\mathrm{m} /---$, stage $\mathrm{r} / \mathrm{l}: 1 / 0)$; bilateral new bone exostosis formation at the anterior and superior margin of iliac auricular facets (stage $r / 1$ : 2/0) and marked muscle attachments of M. gluteus maximus/medius

Stress/bone reactions: an average to severe degree of bilateral periosteal reactions in femora and tibiae; reactive new bone formation on the distal anterior surface of the left fibula (possible soft tissue injury?)

Trauma: bilateral fracture of spina scapulae: well healed (callus) in the medial portion of the spina for the right scapula; signs of healing with porotic new bone formation in the lateral to medial portions of the spina for the left scapula

Degenerative changes: osteophyte formation in $1^{\text {st }}$ to $4^{\text {th }}$ lumbar vertebrae especially localized at the ventral margin of vertebral body; an incision-shaped, longitudinal, anterior-posterior directing change visible in the ventral part of the upper endplate of the $1^{\text {st }}$ sacral vertebra

Other: severe oblique dental wear especially in the upper jaw; some teeth present intravital chipping

Anatomical variation: slight marginal lipping at femur head, bilateral facies poirier to femoral head/neck

Comments: long bone measurements: right humerus $=314 \mathrm{~mm}$, right femur $=437 \mathrm{~mm}$
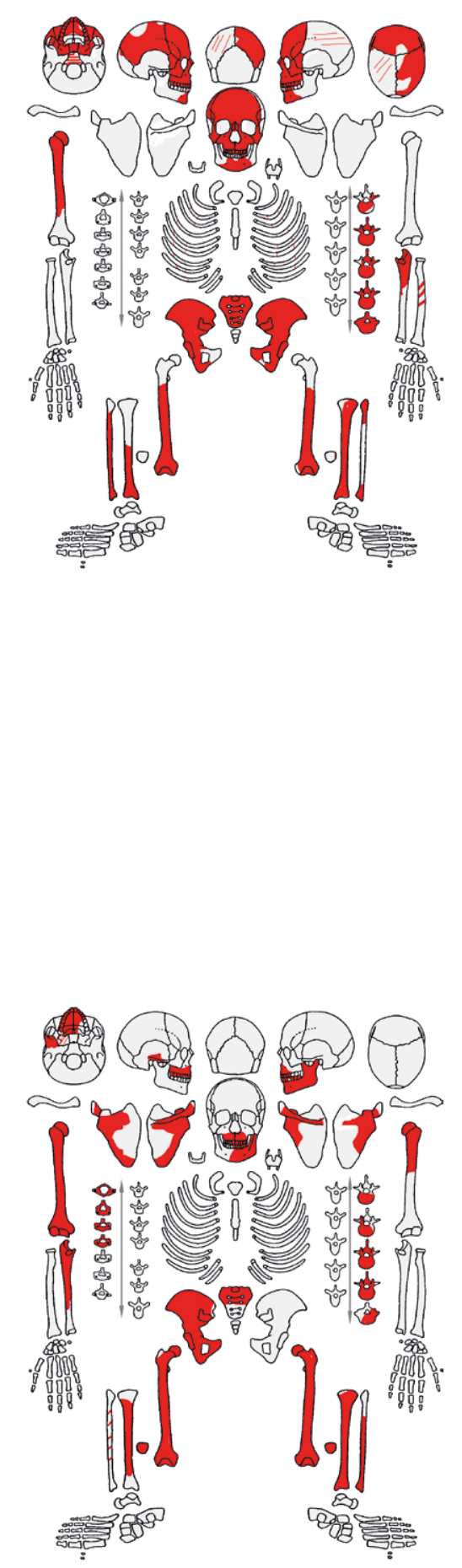
Schleinbach, Feature 1927/3, NHM AA Inv, no. 27677

Sex: undetermined, no sexing characteristics visible in the available frontal bone and maxilla (fragments)

Age: 27-35 years, no cranial suture fusion of C1, dental wear in left upper jaw (IIb)

Body height: -

Bone surface preservation: moderately eroded

Green stains: none detected

Pelvic features, stress/bone reactions, degenerative changes, other:-

Trauma: post-mortal fracture lines in the frontal bone fragments

Anatomical variation: none detected

Comments: no long bone measurements possible

Schleinbach, Feature 1927/4, NHM AA Inv. no. 27678

Sex: undetermined

Age: 4-6 months, diaphyseal length of the right femur $=102 \mathrm{~mm}$

Body height: $60-64 \mathrm{~cm}$

Bone surface preservation: moderately eroded

Green stains: none detected

Stress/bone reactions: none detected

Trauma: none detected

Pelvic features, degenerative changes, other, anatomical variation: -

Comments: measurement of the right femur: diaphyseal length $=102 \mathrm{~mm}$
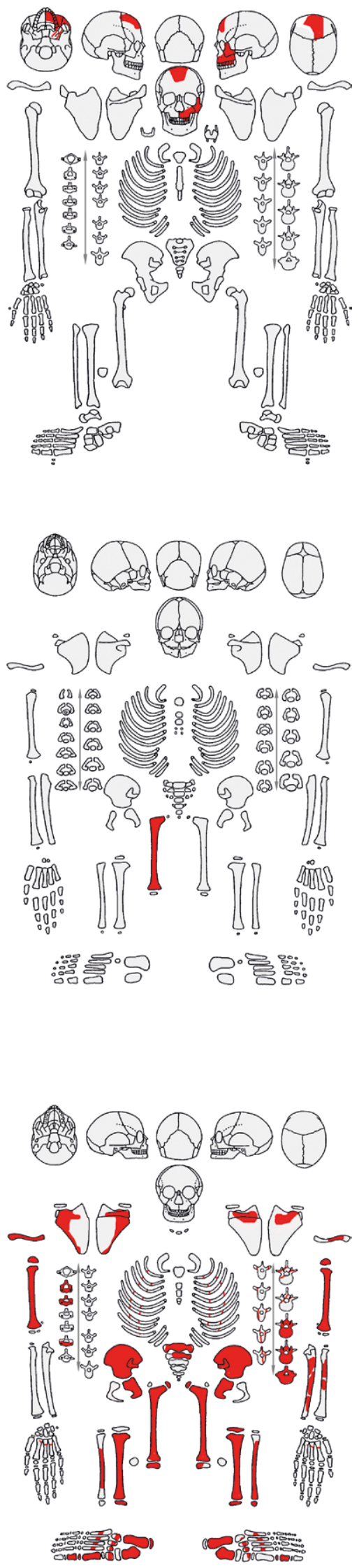

Schleinbach, Feature 1981, NHM AA Inv. no. 27674

Sex: undetermined

Age: 7.5-9 years, epiphyseal fusion (vertebrae), measurements of diaphyseal length

Body height: $120-124 \mathrm{~cm}$

Bone surface preservation: slightly eroded (postcranial remains only)

Green stains: none detected

Pelvic features, stress/bone reactions, trauma:-

Degenerative changes: dens axis ( $2^{\text {nd }}$ cervical vertebra) shows a slight exostosis in the lateral aspect; large porous area at the attachment of $\mathrm{M}$. teres major of both humeri (internal rotation, adduction - possibly due to changes in the workload)

Other, anatomical variation:-

Comments: measurement of diaphyseal length: left humerus $=208 \mathrm{~mm}$, left femur $=302 \mathrm{~mm}$, left tibia $=241 \mathrm{~mm}$; skeletal remains brought to the NHM by Ernst Lauermann in 1987 


\section{Schleinbach 1981/Grube 3 (pit), NHM AA Inv. no. 27617}

Sex: male (proteomic sex identification)

Age: 5-6 years, status of dentition (full primary dentition), measurements of diaphyseal length

Body height: $100-105 \mathrm{~cm}$

Bone surface preservation: slightly eroded (skull and upper extremities)

Green stains: none detected

Pelvic features:-

Stress/bone reactions: intensified pitting and new-bone formation at maxilla, zygomatic bone, squamous part of temporal bone and auditory meatus; plus porotic thickening of external auditory meatus, possibly indicating an 'otitis media'(?) and possibly related changes (osteomyelitis?) of maxillary bones

Trauma: four peri-mortem cranial blunt force traumas: 1. antero-posteriorly-oriented, oval impression fracture with partial penetration of inner and outer table located on the left side of the frontal (one third)/parietal (two thirds) bone in the area of the coronal suture $(60 \times$ $35 \mathrm{~mm}) ; 2$. two smaller, round to oval comminuted lesions with linear and radial fracture lines in the right parietal bone, one in the area of the parietal tubercle and the other next to the sagittal suture $(25 \times 25 \mathrm{~mm}) ; 3$. large, circular depression fracture with complete penetration of the skull bone in the right parietal/occipital bone in the area of lambdoid suture $(\varnothing 4.5 \mathrm{~cm})$

Degenerative changes: none detected

Other: signs of rodent gnawing at the margins of the depression fracture in the right parietal bone, right orbital rim, crista frontalis on the inside (!) of the frontal bone, and foramen magnum

Anatomical variation: persisting foramen Huschke (located in the anteroinferior aspect of the external auditory canal)

Comment: from Stadtmuseum Korneuburg, Inv. Nr. 01068, now NHM Vienna

\section{Schleinbach 1983/Grube 61 (pit), NHM AA Inv. no. 27618}

Sex: undetermined, only six cranial sex characteristics present, indifferent expression Age: $20-40$ years, full secondary dentition, no apical lesion, no intravital tooth loss, pars basilaris fused

TCA age: $\mathbf{2 6 . 8 / 2 3 . 9} \pm \mathbf{5}$ years

Body height: -

Bone surface preservation: moderately eroded (frontal/temporal bone and viscerocranium only)

Green stains: none detected

Pelvic features:-

Stress/bone reactions: orbital roofs exhibit cribra orbitalia with larger porosities and tendency to cluster; stomatitis at the palatine

Trauma: neurocranium: frontal bone reveals a peri-/post-mortem horizontal linear fracture with chipping of the inner table, with continuation into the temporal bone; viscerocranium: nasal bone and superior orbital margin show a peri-/post-mortem horizontal fracture line Degenerative changes:-

Other: peri/post-mortem total chipping of the tooth crowns, only roots of the teeth remain in the alveolar bone

Anatomical variation:-

Comment: from Stadtmuseum Korneuburg, now NHM Vienna
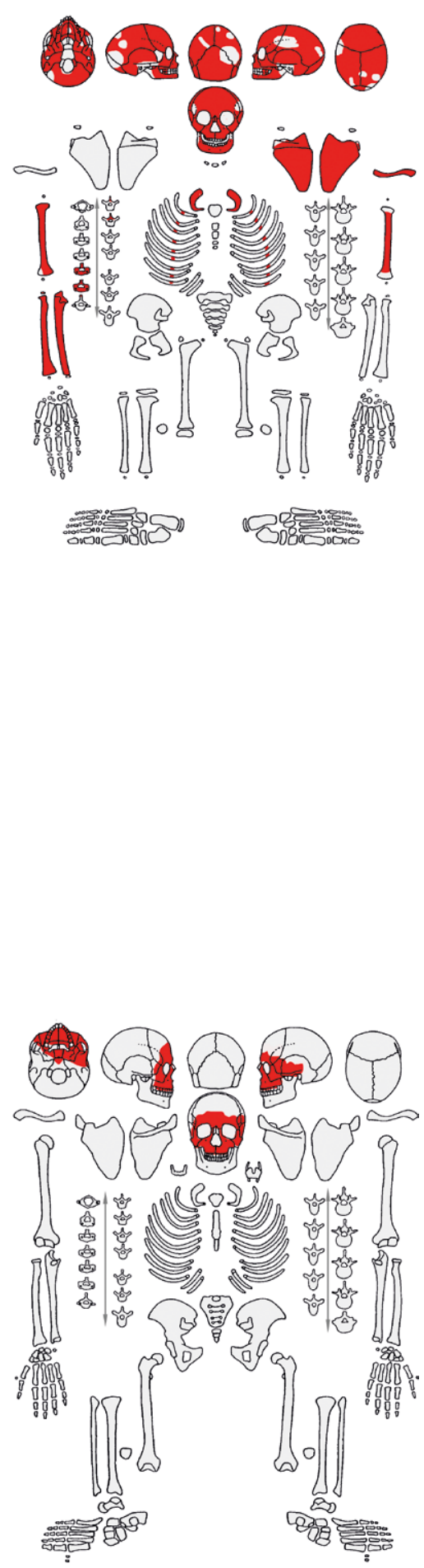
Schleinbach 1983/Grube 71 (pit), NHM AA Inv. no. 27616

Sex: undetermined

Age: 16-18 years, pars basilaris (open), status of dentition (third molars not erupted), dental wear $(\mathrm{IIa} / \mathrm{b})$

TCA age: $13.2 / 15.7 \pm 5$ years

Body height: -

Bone surface preservation: slightly eroded, skull only

Green stains: none detected

Pelvic features: -

Stress/bone reactions: none detected

Trauma: none detected

Degenerative changes:-

Other: a local lytic lesion $(\varnothing$ c. $0.7 \mathrm{~mm})$ on the external surface of the pars basilaris occipitalis between the M. longus capitis (deep cervical flexor muscles); LEH (enamel hypoplasia): severity stage 2; 2-3 fine hypoplastic lines in the maxillary canines, corresponding to a formation age of 2.5 and 3.4 years; further, possible overbite in frontal teeth region (oblique dental wear especially of the $1^{\text {st }}$ incisors)

Anatomical variation: metopic suture

Comments: from Stadtmuseum Korneuburg, now NHM Vienna

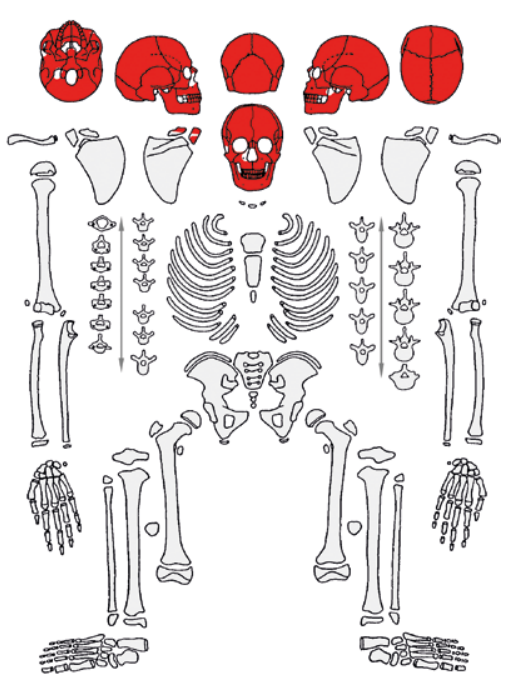

